\title{
The Molecular Control of Calcitonin Receptor Signaling
}

Emma dal Maso, ${ }^{\dagger, \#}$ Alisa Glukhova, ${ }^{\dagger, \# ~ Y u e ~ Z h u, ~}{ }^{\ddagger} \S$ Javier Garcia-Nafria, " Christopher G. Tate," Silvia Atanasio, ${ }^{\perp}$ Christopher A. Reynolds, ${ }^{\perp}$ Erney Ramírez-Aportela, ${ }^{\wedge}$ Jose-Maria Carazo, Caroline A. Hick, ${ }^{\dagger}$ Sebastian G. B. Furness, ${ }^{\dagger}{ }^{\odot}$ Debbie L. Hay, ${ }^{\nabla}{ }^{\odot}$ Yi-Lynn Liang, ${ }^{\dagger}$ Laurence J. Miller, ${ }^{\text {, }}$

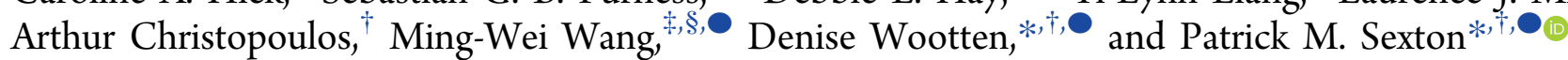

${ }^{\dagger}$ Drug Discovery Biology, Monash Institute of Pharmaceutical Sciences, Monash University, Parkville 3052, Victoria Australia

${ }^{*}$ The National Center for Drug Screening and CAS Key Laboratory of Receptor Research, Shanghai Institute of Materia Medica, Chinese Academy of Sciences, Shanghai 201203, China

${ }^{\S}$ University of Chinese Academy of Sciences, 19A Yuquan Road, Beijing 100049, China

"MRC Laboratory of Molecular Biology, Francis Crick Avenue, Cambridge, CB2 0QH, U.K.

${ }^{\perp}$ School of Biological Sciences, University of Essex, Wivenhoe Park, Colchester CO4 3SQ U.K.

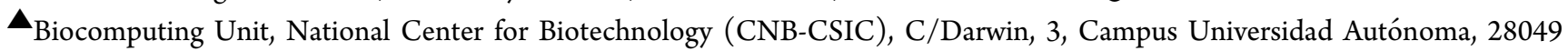
Cantoblanco, Madrid Spain

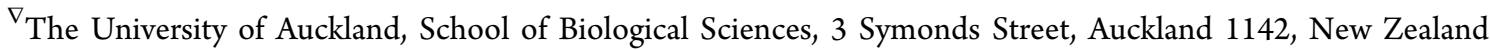

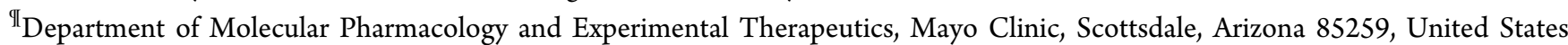

-School of Pharmacy, Fudan University, Shanghai 201203, China

\section{Supporting Information}

\begin{abstract}
The calcitonin receptor (CTR) is a class B G protein-coupled receptor (GPCR) that responds to the peptide hormone calcitonin (CT). CTs are clinically approved for the treatment of bone diseases. We previously reported a $4.1 \AA$ structure of the activated CTR bound to salmon CT (sCT) and heterotrimeric Gs protein by cryo-electron microscopy (Liang, Y.-L., et al. Phase-plate cryo- EM structure of a class B GPCR-G protein complex. Nature 2017, 546, 118-123). In the current study, we have reprocessed the electron micrographs to yield a $3.3 \AA$ map of the complex. This has allowed us to model extracellular loops (ECLs) 2 and 3, and the peptide $\mathrm{N}$-terminus that previously could not be resolved. We have also performed alanine scanning mutagenesis of ECL1 and the upper segment of transmembrane helix 1 (TM1) and its extension into the receptor extracellular domain (TM1 stalk), with effects on peptide binding and function assessed by cAMP accumulation and ERK1/2 phosphorylation. These data were combined with previously published alanine scanning mutagenesis of ECL2 and ECL3 and the new structural information to provide a comprehensive 3D map of the molecular surface of the CTR that controls binding and signaling of distinct CT and related peptides. The work highlights distinctions in how different, related, class B receptors may be activated. The new mutational data on the TM1 stalk and ECL1 have also provided critical insights into the divergent control of cAMP versus pERK signaling and, collectively with previous mutagenesis data, offer evidence that the conformations linked to these different signaling pathways are, in many ways, mutually exclusive. This study furthers our understanding of the complex nature of signaling elicited by GPCRs and, in particular, that of the therapeutically important class B subfamily.
\end{abstract}

KEYWORDS: cryo-electron microscopy, calcitonin receptor, G protein-coupled receptor, receptor structure-function, cell signaling

\section{INTRODUCTION}

Class B1 G protein-coupled receptors (GPCRs) respond to peptide hormones that regulate important physiological functions including bone and glucose homeostasis, energy expenditure, maintenance of vascular tone and immune function. $^{2-4}$ These receptors are also validated targets for diseases including osteoporosis, Paget's disease, diabetes, obesity, and migraine, ${ }^{3-6}$ making understanding of their structure-function important for the development of novel therapeutics.
The calcitonin (CT) receptor (CTR) is a class B1 GPCR that is broadly expressed in tissues and cells including leucocytes, the brain, kidney, gastrointestinal tract, lung, and reproductive organs. ${ }^{3}$ However, it is best recognized for its expression in bone where it is highly expressed on osteoclasts. As a consequence, CTR has been exploited clinically to treat

Received: December 14, 2018

Published: January 11, 2019 


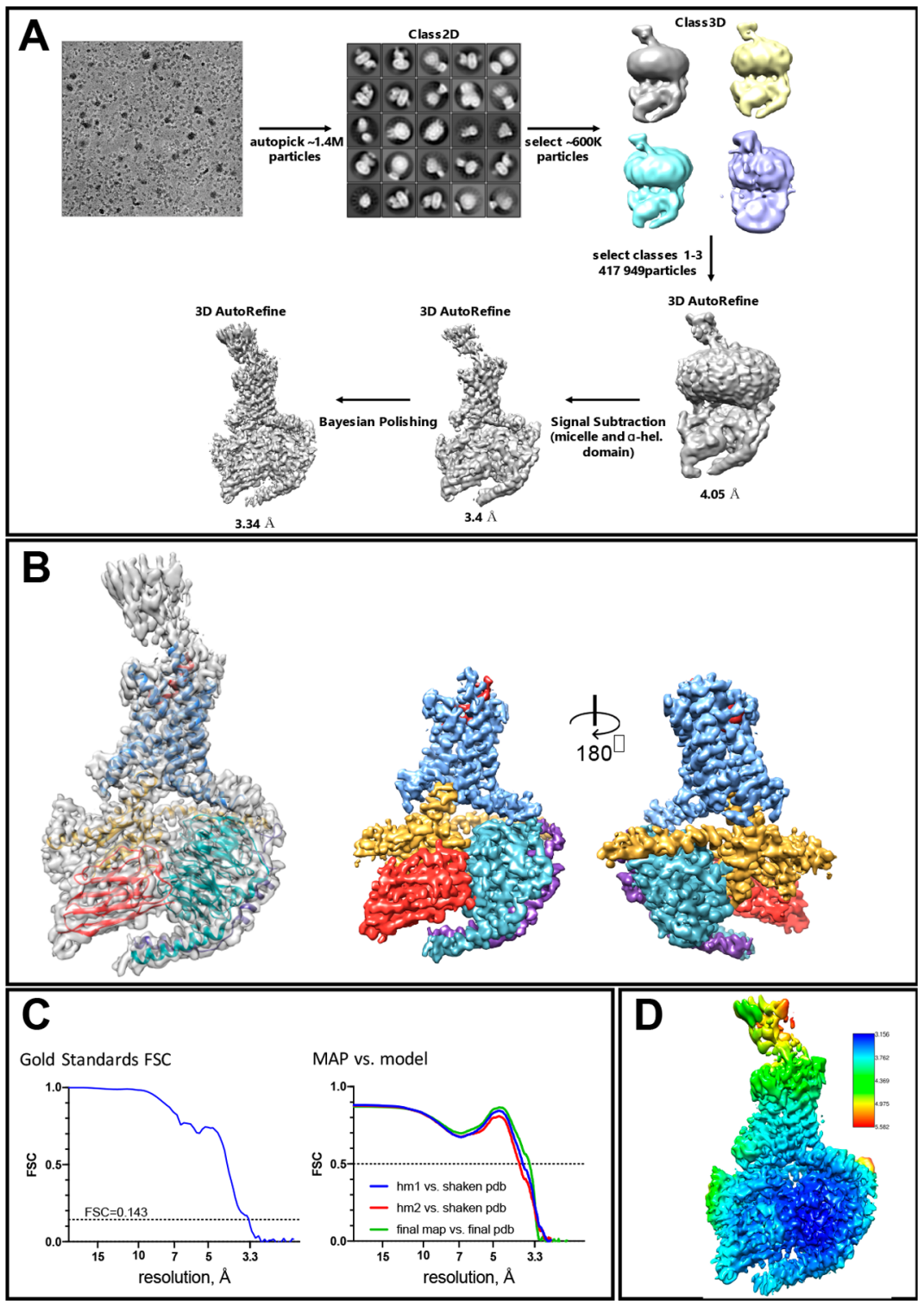

Figure 1. Refined EM map of the sCT:CTR:Gs:Nb35 complex. (A) Workflow for the EM map refinement. (B) Full map (LH panel) sharpened using LocalDeblur, and views of the density for the CTR core (blue), peptide N-terminus (dark red-orange), G protein $\alpha$-subunit (gold), $\beta$-subunit (cyan), $\gamma$-subunit (dark purple), and Nb35 (red) (middle and RH panel). (C) FSC curve for the final map (LH panel) and map validation from half maps (RH panel). (D) LocalResolution-filtered EM map displaying local resolution ( $\AA$ ) colored from highest resolution (dark blue) to lowest resolution (red).

bone disorders including hypercalcemia of malignancy, osteoporosis, and Paget's disease.

CT peptides have been identified from multiple species and subclassified according to sequence conservation and activity into three major classes, human/rodent, artiodactyl (e.g., porcine $\mathrm{CT}$ ) and teleost/avian (including salmon, eel, and chicken). ${ }^{7}$ Human and fish/eel CTs have been used clinically, although they have distinct properties for engagement and activation of CTRs. $^{8-10}$

The CTR can also interact with the receptor activitymodifying protein (RAMP) family to form distinct amylin and CGRP receptor phenotypes. ${ }^{4}$ In a recent study, we used alanine scanning mutagenesis of extracellular loops (ECL) 2 and 3 to reveal peptide and pathway specific differences in the role of these two loops. ${ }^{11}$

To provide additional insights into CTR structure and function, we solved a $4.1 \AA$ structure of the activated CTR in complex with heterotrimeric $\mathrm{G}$ protein and salmon $\mathrm{CT}$ ( $\mathrm{sCT}$ ) that was the first GPCR structure solved by cryo-electron microscopy (cryo-EM). ${ }^{1}$ While this revealed key features of active state class B1 GPCRs, it had limited resolution, particularly for the ECLs and for the peptide. In the current study, we have taken advantage of recent advances in cryo-EM software to reanalyse our original cryo-EM images enabling improvement in the global resolution of CTR map to $\sim 3.3 \AA$. This provides enhanced resolution of receptor side chains, including ECL2 and ECL3, and in the N-terminus of the peptide that binds to the receptor core. We have combined this with new data comprising alanine mutagenesis of ECL1 of the receptor and upper segment of transmembrane domain (TM) 1 and its extension that links TM1 to the extracellular domain (ECD) (herein referred to as the TM1 stalk), and reassessment of alanine mutants of ECL2 and ECL3, in light of the new structural data. This gives enhanced details of the 

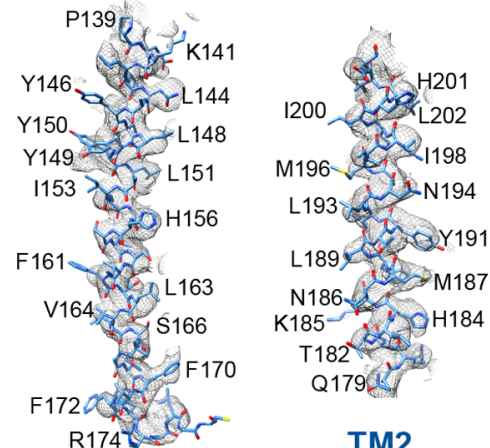

TM2
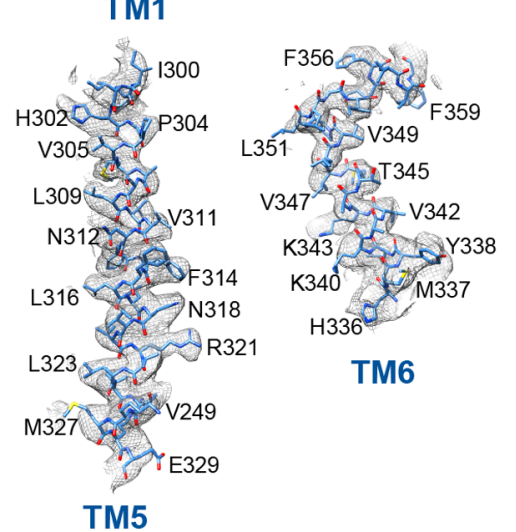

TM6

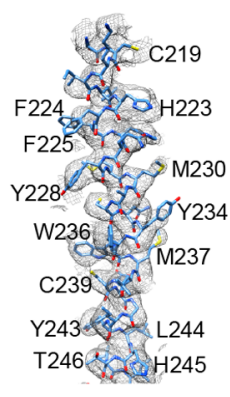

TM3

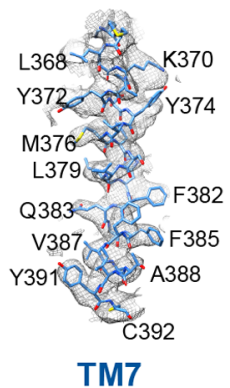

TM7

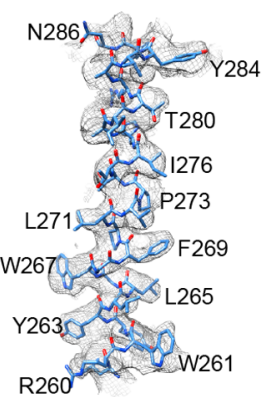

TM4

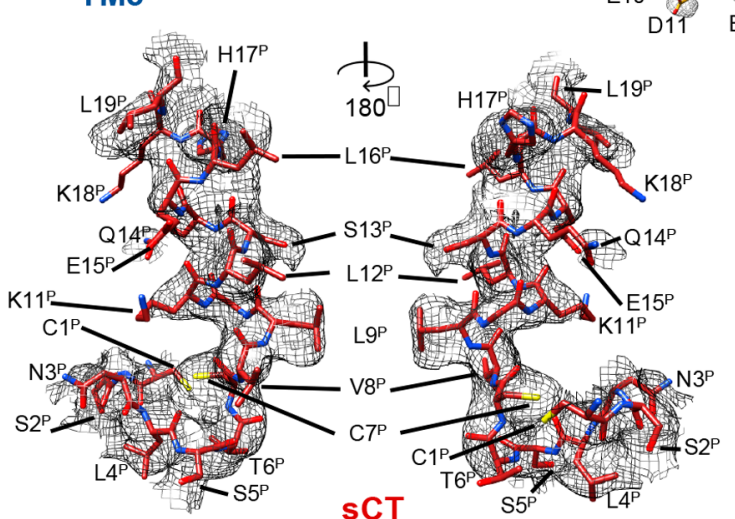

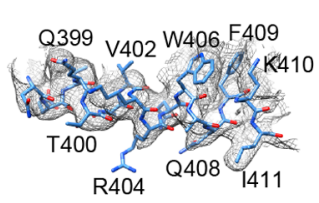

H8

Gas- $\alpha$ N
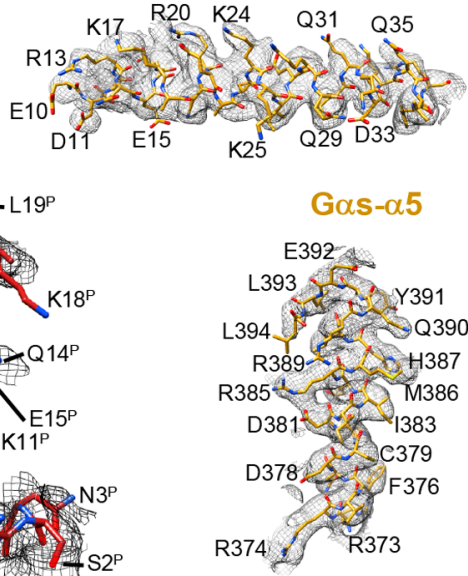

Figure 2. Atomic coordinates of the sCT:CTR:Gs complex in the cryo-EM density map. Cryo-EM density map and model are shown for all seven transmembrane helices and $\mathrm{H} 8$ of the receptor; the sCT peptide (amino acids 1-19), the N-terminal $(\alpha \mathrm{N})$, and C-terminal $(\alpha \mathrm{H} 5) \alpha$-helices of the G $\alpha$ s-Ras domain are also shown. Superscript P indicates residues of sCT. The EM map was zoned at $2.5 \AA$ around the protein segments.
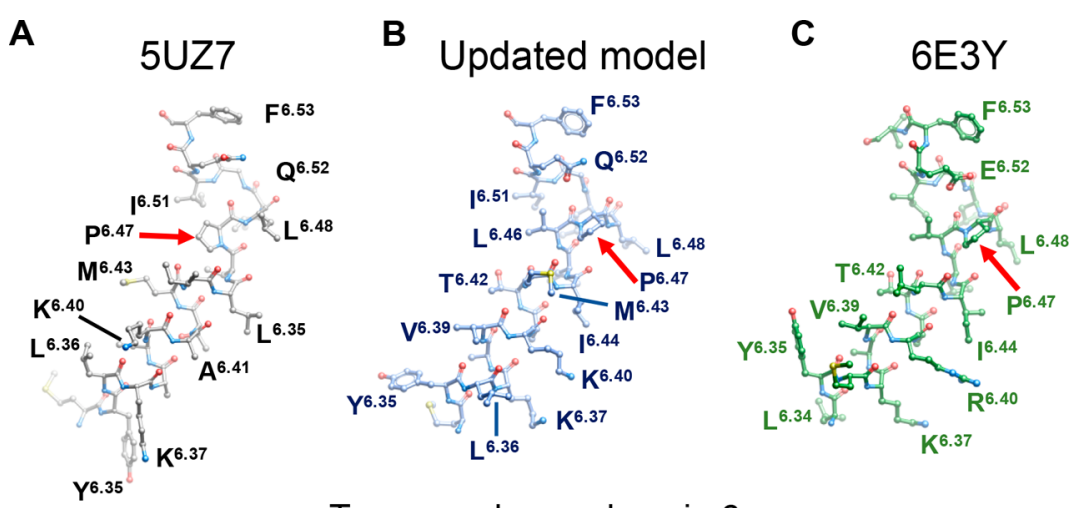

Transmembrane domain 6

Figure 3. Improved modeling of transmembrane domain 6. (A) Model of TM6 from PDB 5UZ7, derived from the $4.1 \AA$ EM map of the active CTR complex. (B) Model of TM6 from the current map, illustrating changed registry of amino acids below Pro. ${ }^{6,47}$ (C) Model of TM6 from the related CLR of the CGRP receptor (PDB 6E3Y) illustrating conservation in the position of side-chains between CTR and CLR. 

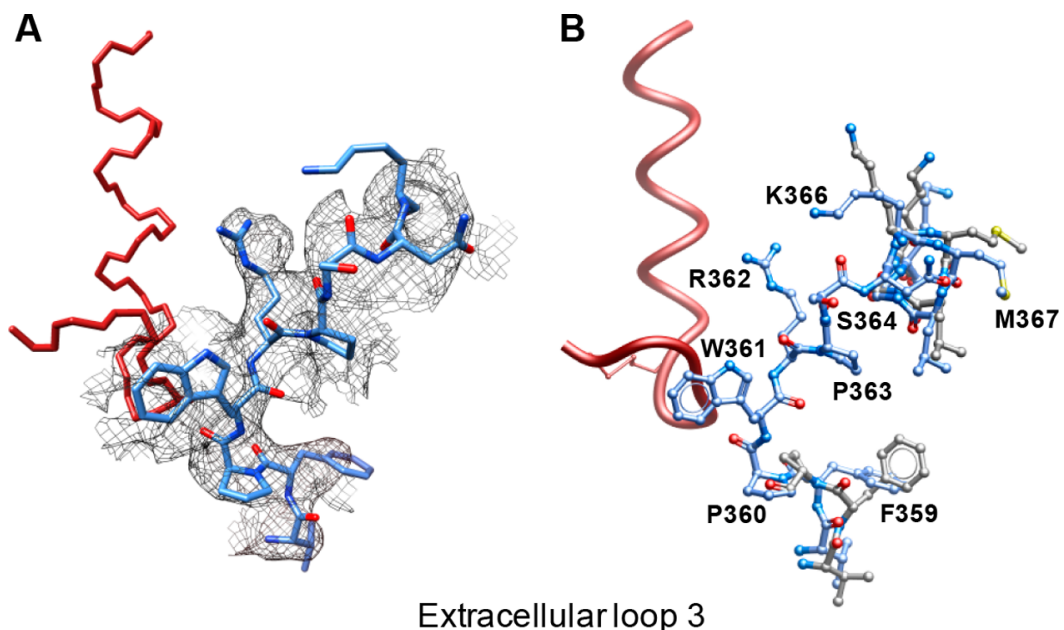

Figure 4. Modeling of CTR ECL3 in the active state complex. (A) Cryo-EM density map and model of ECL3. (B) Model of ECL3 illustrating the position of loop side-chains.

molecular control of CTR activation by CT and related peptides.

\section{RESULTS AND DISCUSSION}

A $3.3 \AA$ Cryo-EM Map of the sCT:CTR:Gs:Nb35 Complex. We have utilized advances in cryo-EM data refinement to reprocess the original micrographs used to report the $4.1 \AA$ structure of the complex. ${ }^{1}$ Approximately 1.4 million particles were autopicked and subject to initial $2 \mathrm{D}$ classification, from which $\sim 600,000$ particles were selected for 3D classification (Figure 1A). This yielded 4 classes, with classes 1-3 containing 417949 particles, then subject to autorefinement to yield an initial map at $4.1 \AA$. Signal subtraction of the micelle and mobile $\alpha$-helical domain of the Gs $\alpha$ subunit, following by further refinement provided a map at $3.4 \AA$ global resolution. Subsequent use of Bayesian polishing in RELION 3 provided a small additional increase in resolution but further increased the map quality to yield the final $3.34 \AA$ map (Figure $1 \mathrm{~A}-\mathrm{C}$ ). As previously noted for the lower resolution map, ${ }^{1}$ the highest local resolution was seen for the $G$ protein and receptor core with lower resolution for the more mobile ECLs and receptor ECD (Figure 1B,D). The map provided good side-chain resolution for most of the CTR TM helices, as well as the $G$ protein (Figure 2). We used this map to remodel the protein complex, including the peptide $\mathrm{N}$ terminus and ECL2 and ECL3, regions that were not previously modeled due to lack of robust density.

In general, there was good agreement with the deposited model (PDB 5UZ7) across the receptor TM, with the exception of TM6 (Supplementary Figure 1, Figure 3). Owing to the weak density in the original map, the kink around the conserved $\mathrm{P}^{6.47}-\mathrm{X}-\mathrm{X}-\mathrm{G}^{6.50}$ (superscript numbers refer to the Wootten numbering scheme for class B GPCRs ${ }^{12}$ ) motif was incorrectly modeled leading to residues below $\mathrm{P}^{6.47}$ being out of register by one amino acid (Figure $3 \mathrm{~A}$ and $3 \mathrm{~B}$ ). As the first ever active class B GPCR solved there was no equivalent structure available for comparison. Subsequently, active structures of the glucagon-like peptide-1 receptor (GLP$1 \mathrm{R}),{ }^{13,14}$ and the closely related calcitonin gene related peptide receptor $(\mathrm{CGRPR})^{15}$ were solved. Structural alignment between the remodeled CTR and CT-receptor-like receptor (CLR) in the CGRPR (PDB 6E3Y) revealed that they exhibited very close location of TM6 side chains (Figure
3B,C), and the positionally equivalent residues in the GLP-1R have similar orientation, ${ }^{13,14}$ confirming that class B GPCRs have similar organization of key TM6 side chains that are likely important for $\mathrm{G}$ protein engagement. ${ }^{16}$

In the new map, there was a well resolved density for most residues in ECL3 (Figure 4A) enabling this to be modeled for the first time (Figure 4B). The side-chains of $\mathrm{P} 360^{\mathrm{ECL} 3}$, $\mathrm{W} 361^{\mathrm{ECL} 3}, \mathrm{R} 362^{\mathrm{ECL} 3}, \mathrm{P} 363^{\mathrm{ECL} 3}$, and $\mathrm{S} 364^{\mathrm{ECL} 3}$ displayed clear density with W361 ${ }^{\mathrm{ECL}}, \mathrm{R} 362^{\mathrm{ECL3}}$ oriented toward the agonist peptide, sCT (Figure 4A,B), while the backbone of P360 $0^{\mathrm{ECL} 3}$ formed a hydrogen-bond with $\operatorname{Ser}^{\mathrm{P}}$ of the peptide (Figure $4 C, D$ ). These interactions are consistent with our previously reported alanine mutagenesis of ECL3 where, with the exception of $\mathrm{S} 364^{\mathrm{ECL} 3}$, alanine mutation had peptide and pathway specific effects on receptor function. ${ }^{11} \mathrm{~K} 366^{\mathrm{ECL} 3}$ had only limited side-chain density, indicating that it forms only weak interactions with sCT. The remainder of ECL3 was not in proximity to the peptide.

In the originally published map, there was only limited density for ECL2 and only the backbone was modeled ${ }^{1}$ (Figure $5 A, B)$. In the current map, resolved density was observed for all of ECL2, enabling more accurate placement of the backbone, as well as modeling of the amino acid side-chains (Figure 5C, Supplementary Figure 2). The CTR has the closest homology to CLR, including ECL2 (Figure 6). There was strong conservation in both the backbone position and packing of residues between CTR and CLR (Figure 5A,C,D), with $\mathrm{R} 281^{\mathrm{ECL} 2}$ and $\mathrm{W} 290^{\mathrm{ECL} 2}$ packed within the core of the loop. The structure of the loop was supported by polar interactions between, in particular, $\mathrm{R} 281^{\mathrm{ECL2}}, \mathrm{D} 287^{\mathrm{ECL} 2}$, and $\mathrm{S} 292^{\mathrm{ECL} 2}$, as well as predicted H-bonding between backbone atoms, including $\mathrm{N} 288^{\mathrm{ECL} 2}-\mathrm{L} 291^{\mathrm{ECL} 2}$ and $\mathrm{R} 281^{\mathrm{ECL} 2}-\mathrm{N} 286^{\mathrm{ECL} 2}$.

In the current map, there was also improved density for most of the $\mathrm{N}$-terminal residues of $\mathrm{SCT}$ (between residues 1 and 19) that enabled this to be formally modeled into density for the first time (Figure 2, Figure 6). The peptide N-terminus forms extensive, primarily hydrophobic, interactions with the receptor core. The far $\mathrm{N}$-terminus exhibits a loop between $\mathrm{Cys}^{\mathrm{P}}$ and $\mathrm{Cys}^{\mathrm{P}} \mathrm{P}^{\mathrm{T}}$ that is critically important for agonist activity: deletion of this segment yielded the high affinity antagonist/

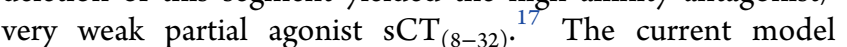
identified H-bond interactions between $\operatorname{Ser} 5^{\mathrm{P}}$ and the backbone of $\mathrm{P} 360^{6.57}$ and $\mathrm{F} 359^{6.56}$, and the hydroxyl of 


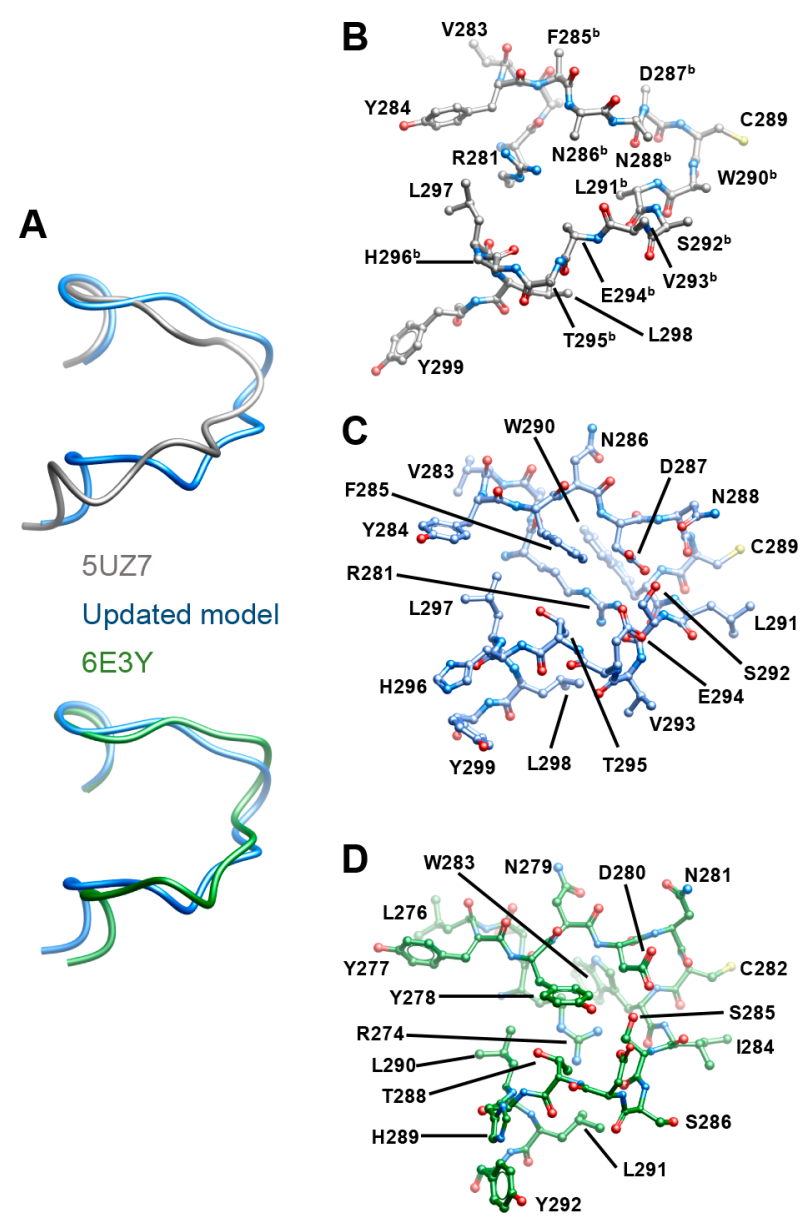

Figure 5. Modeling of CTR ECL2 in the active state complex. (A) Comparison of the backbone of CTR and CLR ECL2 in the original model (PDB 5UZ7, gray), the current CTR model (blue) and CLR of the CGRP receptor (PDB 6E3Y, green). (B) CTR ECL2 from PDB 5UZ7. (C) New model of CTR ECL2 from the reprocessed map. (D) CLR from ECL2 (PDB 6E3Y). The EM density for ECL2 is shown in Supplementary Figure 2.

$\mathrm{Y}_{372^{7.38}}$ at the boundary of ECL3, while $\mathrm{Thr}^{\mathrm{P}}$ forms a $\mathrm{H}-$ bond with $\mathrm{H}_{302} 2^{5.40}$ (Figure 6C,D); the latter is consistent with previously predicted interaction between these residues, ${ }^{1}$ and is also conserved between CGRP Thr6 ${ }^{\mathrm{P}}$ and $\mathrm{H}^{5.40}$ of CLR in the CGRP receptor. ${ }^{15}$ Ser $2^{\mathrm{P}}$ forms a H-bond with the hydroxyl of $\mathrm{Y} 299^{5.37}$, while the backbone nitrogen of $\mathrm{Cys}^{\mathrm{P}}$ is within $\mathrm{H}$ bond distance of backbone atoms of $\mathrm{T} 295^{\mathrm{ECL} 2}$ and $\mathrm{V} 293^{\mathrm{ECL} 2}$. The peptide N-terminal loop formed only limited interaction with ECL2, including hydrophobic interactions with $\mathrm{L} 298^{\mathrm{ECL} 2}$ and $\mathrm{V} 293^{\mathrm{ECL} 2}$. This is in agreement with the limited effect of mutations within ECL2 on the binding affinity of CT peptides. ${ }^{11}$ As previously predicted from the available density, sCT displays an amphipathic $\alpha$-helix from $\mathrm{Val} 8^{\mathrm{P}}-\mathrm{Leu} 19^{\mathrm{P}}$, and the hydrophobic face forms an extended interface, principally with hydrophobic residues of TM1 and TM7 (Figure 6A,B,D). In the current model $\mathrm{Gln} 14^{\mathrm{P}}$ is within H-bond distance of $\mathrm{E} 294^{\mathrm{ECL} 2}$; however, there was little density for the peptide sidechain, indicating that it is mobile and is likely to form only weak, transient interactions. Within the peptide, there was very little interaction with ECL1 residues and this was limited to weak hydrophobic interaction with $\mathrm{H} 201^{\mathrm{ECL} 1}\left(\mathrm{Ser} 13^{\mathrm{P}}\right)$ and V205 (His $17^{\mathrm{P}}$ ) (Figure $\left.6 \mathrm{D}\right)$. There were additional interactions between the $\mathrm{C}$-terminal extension of the peptide helix that bind within the receptor core and the TM1 stalk; however, there was only limited density for the receptor in this region of the map, likely due to averaging of the signal from the large number of particles, suggesting that this is likely to an area of mobility in the agonist-receptor complex.

Importance of the CTR Extracellular Surface on Receptor Function. In addition to the TM1 stalk, ECL1 was still poorly resolved in the new map and could not be directly modeled. To gain further insight into the importance of the extracellular surface of the receptor in the binding and activation of the receptor by different $\mathrm{CT}$ and related peptide agonists, we performed alanine scanning of ECL1 (H201C219) and the TM1 stalk (S129-L151), and analyzed each of the mutants for cell surface expression (Figure 7, Table 1), binding affinity in competitive radioligand binding assays (Figure 8, Supplementary Figures 3-6, Table 1), and functional response (cAMP formation and ERK1/2 phosphorylation) for each peptide (Figures 10, 11, 13, and 14, Supplementary Figures 7-16, Tables 2 and 3). The results of these experiments were combined with our previously published mutagenesis of ECL2 and ECL $3^{11}$ and mapped onto the revised structure of the sCT:CTR:Gs complex (Figures 9, 12 and 15). In this revised structure, residues and side-chains with no visible density in the cryo-EM map were independently modeled into the available structure, and the receptor $\mathrm{ECD}$ and the far peptide $\mathrm{C}$-terminus rigid body fit into the map. This full-length structure was subjected to a short MD simulation (200 ns) to resolve energetically unfavorable interactions and yield the model used to visualize the data (Figures 9, 12, and 15).

Receptor Expression. Cell surface expression was assessed by antibody binding to the c-Myc tag incorporated at the far $\mathrm{N}$-terminus of the receptor and analyzed by FACS. Only $\mathrm{C} 134^{\mathrm{ECD}} \mathrm{A}$ in the TM1 stalk, and $\mathrm{C} 219^{3.29} \mathrm{~A}$ in ECL1 had marked negative impact on receptor expression $(<20 \%$ of WT) at the cell surface. Increased expression was seen with alanine mutants of $\mathrm{S} 129^{\mathrm{ECD}}, \mathrm{Y} 131^{\mathrm{ECD}}, \mathrm{F} 137^{1.28}, \mathrm{E} 140^{1.31}, \mathrm{~K} 141^{1.32}$, $\mathrm{L} 142^{1.33}, \mathrm{~N}_{144^{1.35}}, \mathrm{Y}_{146^{1.37}}, \mathrm{~V} 147^{1.38}, \mathrm{Y} 149^{1.40}$, and $\mathrm{Y} 150^{1.41}$, in the TM1 stalk (Figure 7 upper panel, Table 1). There was a more limited effect on ECL1 with a small decrease in expression of the $\mathrm{H}_{20} \mathrm{1}^{2.67} \mathrm{~A}$ mutant and increased expression of the $\mathrm{L} 202^{2.68}, \mathrm{P} 207^{\mathrm{ECL} 1}, \mathrm{E} 209^{\mathrm{ECL} 1}, \mathrm{~V} 212^{\mathrm{ECL} 1}, \mathrm{P} 216^{3.26}$, and S218 $8^{3.28}$ to alanine mutants (Figure 7 lower panel, Table 1, Figure 9B).

Peptide Affinity (Competition Binding). The impact on peptide affinity was assessed by competition with ${ }^{125} \mathrm{I}$ $\mathrm{sCT}_{(8-32)}$ binding. In this assay, amylin and CGRP were not evaluated due to limited competition for binding over the concentrations used (up to $1 \mu \mathrm{M}$ ). Within the TM1 stalk, affinity for the poorly expressed $\mathrm{C} 134^{\mathrm{ECD}} \mathrm{A}$ mutant could not be assessed. There was also insufficient robustness to determine $\mathrm{p} K_{\mathrm{i}}$ values for the $\mathrm{N} 135^{\mathrm{ECD}} \mathrm{A}$ mutant for all except for $\mathrm{sCT}$, the $\mathrm{N} 130^{\mathrm{ECD}} \mathrm{A}$ mutant for $\mathrm{sCT}_{(8-32)}$ and hCT, and the $\mathrm{Y}_{131}{ }^{\mathrm{ECD}} \mathrm{A}$ mutant for hCT and $\mathrm{sCT}$ (Figure 8, Table 1). Of the mutants where a robust inhibition curve could be derived, none significantly altered $\mathrm{sCT} \mathrm{p} K_{\mathrm{i}}$ (Figure $8 \mathrm{~B}$, Table 1, Supplementary Figure $4 \mathrm{~A}-\mathrm{D}$ ). There was reduced $\mathrm{p} K_{\mathrm{i}}$ of $\mathrm{sCT}_{(8-32)}$ for alanine mutants of $\mathrm{S} 129^{\mathrm{ECD}}, \mathrm{Y} 131^{\mathrm{ECD}}, \mathrm{L} 142^{1.33}$, Y146 ${ }^{1.37}, \mathrm{~L}_{148^{1.39}}, \mathrm{Y} 150^{1.41}$, and L151 ${ }^{1.42}$ (Figure 8A, Table 1, Supplementary Figure $3 \mathrm{~A}-\mathrm{D})$. Reduced $\mathrm{hCT} \mathrm{p} K_{\mathrm{i}}$ was observed for all mutants that affect $\mathrm{sCT}_{(8-32)}$, but reduced affinity was also seen with the M133 $3^{\mathrm{ECD}}, \mathrm{T}_{1} 138^{1.29}, \mathrm{~K} 141^{1.32}$, $\mathrm{K} 143^{1.34}$, and $\mathrm{Y} 149^{1.40}$ to alanine mutants (Figure $8 \mathrm{C}$, Table 1, 

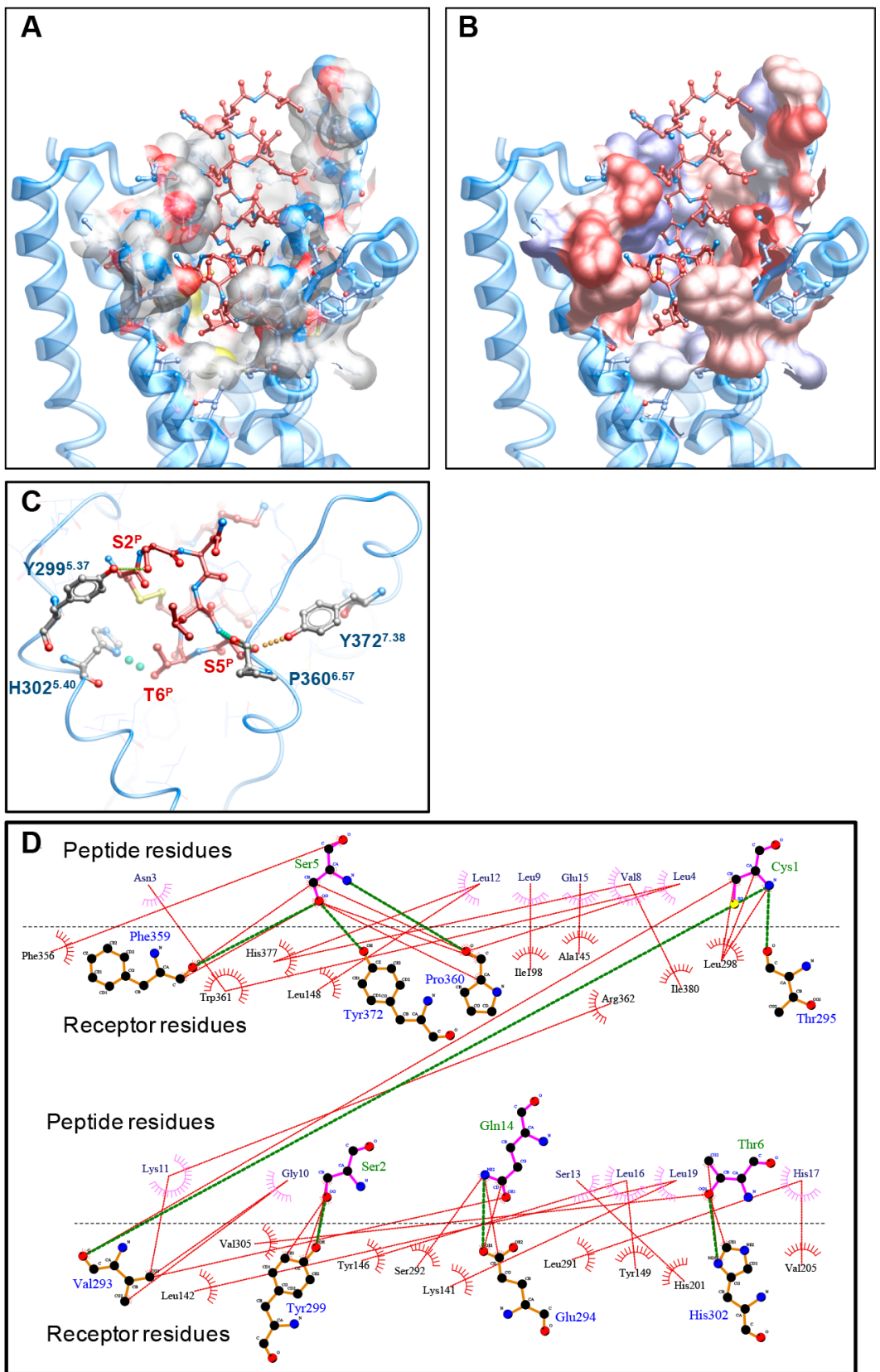

Figure 6. Modeling of sCT binding to the CTR core. Panels A and B illustrate the CTR binding surface colored according to atom type (A) or hydrophobicity (B) in ICM. The receptor ECD has been omitted for clarity. (C) Key hydrogen-bond interactions between the sCT N-terminus and CTR (H-bonds are differentially colored and sized in ICM according to bond strength). (D) Summary of the peptide-receptor interface calculated and displayed by LigPlot+. Green lines illustrate H-bonds. Red lines illustrate hydrophobic interactions. The extension of hydrophobic interaction from each residue is also displayed (sCT, pink; CTR, red).

Supplementary Figure 5A-D). There was greater impact of mutations to ECD proximal residues on $\mathrm{pCT} \mathrm{p} K_{\mathrm{i}}$ with reductions in affinity observed for all residues from $129^{\mathrm{ECD}}$ $138^{1.29}$. Of the remaining mutants, only alanine mutants of $\mathrm{K} 141^{1.32}, \mathrm{~L} 142^{1.33}, \mathrm{~L} 148^{1.39}$, and $\mathrm{Y} 149^{1.40}$ reduced pCT affinity (Figure 8D, Table 1, Supplementary Figure 6A-D). Within ECL1, there was very little impact on peptide $\mathrm{p} K_{\mathrm{i}}$, with the

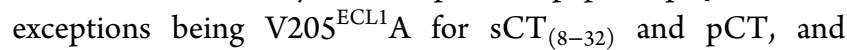
L202 ${ }^{2.68} \mathrm{~A}$ for hCT (Figure $8 \mathrm{E}-\mathrm{H}$, Supplementary Figures $3 \mathrm{E}-$ $\mathrm{H}$ to $6 \mathrm{E}-\mathrm{H}$ ). The poorly expressed $\mathrm{C} 219^{3.29} \mathrm{~A}$ was not assessed due to insufficient response in the concentration range assessed.
While there was only limited effect on binding $\mathrm{p} K_{\mathrm{i}}$ for $\mathrm{sCT}$ and $\mathrm{sCT}_{(8-32)}$, mapping of the mutational data for effect on peptide $\mathrm{p} K_{\mathrm{i}}$ for both the current study and previous work on ECL2 and ECL $3^{11}$ revealed that the loss of affinity for hCT and pCT was principally associated with amino acids that formed the interface between the peptide and receptor in the model. This was particularly true for amino acids along the hydrophobic interface of TM1 and TM7, and proximal residues of ECL3 (Figure 9E,F). Of note, the extension of the TM1 stalk $\left(\mathrm{S} 129^{\mathrm{ECD}}-\mathrm{N} 135^{\mathrm{ECD}}\right)$ resides within receptor ECD, with $\mathrm{C} 134^{\mathrm{ECD}}$ forming a disulfide bond to $\mathrm{C} 95^{\mathrm{ECD}}$, and this is one of three conserved ECD disulfide bonds seen in class B GPCRs ${ }^{3}$. Moreover, $\mathrm{S} 129^{\mathrm{ECD}}-\mathrm{Y} 131^{\mathrm{ECD}}$ forms back- 


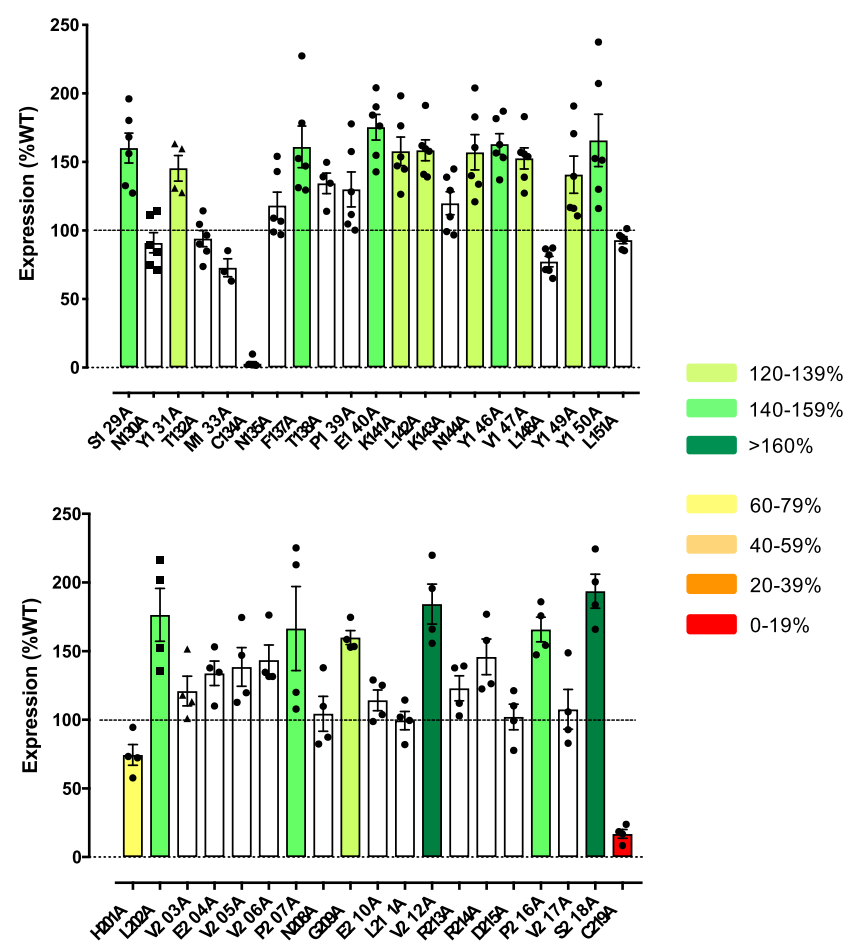

Figure 7. Effect of alanine mutation on the cell surface expression of the CTR. (Upper panel) Effect of alanine mutation of the TM1 stalk on CTR expression monitored by FACS of anti-c-Myc antibody binding to the $\mathrm{N}$-terminal c-Myc epitope on the receptor. (Lower panel) Effect of alanine mutation of ECL1. Data are normalized to the expression of the wild-type (WT) receptor (100\%). Significant differences in the level of cell surface expression were determined by one-way ANOVA followed by Dunnett's post-test comparison to the WT. $P<0.05$ was used to denote significance (marked by an asterisk), and colored according to the magnitude of change. Individual experimental " $n$ " are shown within the bars.

bone $\mathrm{H}$-bond interactions with the C-terminal Pro- $\mathrm{NH}_{2}$ of $\mathrm{sCT}^{18}$ and, presumptively, related CT peptides likely underlie the importance of the integrity of this region of the receptor. Interestingly, in contrast to other class B GPCRs such as the glucagon-like peptide-1 receptor (GLP-1R), there was a lesser impact of alanine mutation of residues of ECL2 that likely reflects the limited role of ECL2 side-chains in the peptide binding interface. Intriguingly, the mutations had only limited impact on the $\mathrm{p} K_{\mathrm{i}}$ of $\mathrm{sCT}$ (Figure 9D) or $\mathrm{sCT}_{(8-32)}$ (Figure $9 \mathrm{C})$, and this likely reflects the tighter binding of the teleost peptide ${ }^{8,10,19}$ such that the individual receptor mutation has limited effect on the overall affinity.

Functional Affinity. Concentration response curves were established for each of the peptides in functional assays of cAMP accumulation and ERK1/2 phosphorylation (Supplementary Figures 7-16), and data were analyzed using the operational model for agonism to derive pathway specific estimates of functional affinity $\left(\mathrm{p} K_{\mathrm{A}}\right)$ and efficacy (tau) (Figures 10, 11, 13, and 14, Tables 2 and 3). The latter was corrected for differences in cell surface expression.

The alanine mutation had only limited significant effect on $\mathrm{p} K_{\mathrm{A}}$ estimates from cAMP accumulation experiments across the TM1 stalk and ECL1 (Figure 10, Table 2). While there were trends toward significant effects for a number of mutants, only the following achieved statistical significance. For sCT there was reduced $\mathrm{pK}$ A for $\mathrm{N} 130^{\mathrm{ECD}} \mathrm{A}$, while for hCT significant reductions were seen for $\mathrm{N} 130^{\mathrm{ECD}} \mathrm{A}, \mathrm{Y} 131^{\mathrm{ECD}} \mathrm{A}$,
$\mathrm{M} 133^{\mathrm{ECD}} \mathrm{A}$, and $\mathrm{Y} 149^{1.40} \mathrm{~A}$ in the TM1 stalk and $\mathrm{L} 202^{2.68} \mathrm{~A}$ and $\mathrm{V} 205^{\mathrm{ECL} 1} \mathrm{~A}$ for ECL1. For $\mathrm{pCT}$, reductions in $\mathrm{p} K_{\mathrm{A}}$ were seen for the $\mathrm{N} 130^{\mathrm{ECD}} \mathrm{A}$ and $\mathrm{M} 133^{\mathrm{ECD}} \mathrm{A}$ mutants in the TM1 stalk and $\mathrm{V}_{20}{ }^{\mathrm{ECL} 1} \mathrm{~A}$ in ECL1. The data for amylin and CGRP had higher variance. Of these, the only statistically significant effect was for amylin with the M133 ${ }^{\mathrm{ECD}} \mathrm{A}$ mutant in the TM1 stalk.

Because of the weak response of amylin and CGRP in stimulation of $\mathrm{pERK}$, only limited data sets could be fitted with the operational model (Table 3). For the CT peptides, a significant decrease in $\mathrm{p} K_{\mathrm{A}}$ was observed for $\mathrm{sCT}$ for the $\mathrm{N} 130^{\mathrm{ECD}} \mathrm{A}$ mutant, although there were trends toward an effect for other mutants in the TM1 stalk (Figure 11, Table 3), with no effect of ECL1 mutants. For hCT, there was insufficient robustness in response to determine $\mathrm{p} K_{\mathrm{A}}$ for the $\mathrm{N} 130^{\mathrm{ECD}} \mathrm{A}$ mutant, with significant loss of $\mathrm{p} K_{\mathrm{A}}$ for $\mathrm{Y} 131^{\mathrm{ECD}}, \mathrm{L} 142^{1.33} \mathrm{~A}$, $\mathrm{Y} 146^{1.37} \mathrm{~A}$, and $\mathrm{Y} 149^{1.40} \mathrm{~A}$ in the TM1 stalk, and $\mathrm{L} 202^{2.68} \mathrm{~A}$, $\mathrm{V} 205^{\mathrm{ECL} 1} \mathrm{~A}, \mathrm{P} 207^{\mathrm{ECL} 1} \mathrm{~A}, \mathrm{G} 209^{\mathrm{ECL} 1} \mathrm{~A}$, and $\mathrm{V} 212^{\mathrm{ECL} 1} \mathrm{~A}$ in ECL1. There was greater variance in the data for $\mathrm{pCT}$ where many alanine mutants trended toward reduced $\mathrm{p} K_{\mathrm{A}}$, of which only $\mathrm{E} 140^{1.31} \mathrm{~A}$ and $\mathrm{L} 142^{1.33} \mathrm{~A}$ achieved statistical significance. Only the $\mathrm{P} 207^{\mathrm{ECL} 1} \mathrm{~A}$ mutation within ECL1 significantly reduced $\mathrm{p} K_{\mathrm{A}}$ (Figure 11, Table 3).

Mapping of the data onto the $3 \mathrm{D}$ receptor model demonstrated parallels between the observed effect of mutation on cAMP $\mathrm{p} K_{\mathrm{A}}$ and $\mathrm{p} K_{\mathrm{i}}$ from binding assays for each of the CT peptides (Figures 9 and 12), which is consistent with Gs coupling being the primary signaling pathway for these peptides and the allosteric influence of Gs on binding of $\mathrm{hCT}$ and $\mathrm{sCT}^{10}$. Of note, $\mathrm{sCT}$ binding is effectively insensitive to the effects of excess guanine nucleotide, ${ }^{8,19}$ and this is reflected in the limited effect of mutation on $\mathrm{p} K_{\mathrm{i}}$ and functional $\mathrm{p} K_{\mathrm{A}}$. Interestingly, the pattern of effect of mutation on $\mathrm{pERK} \mathrm{pK} \mathrm{A}_{\mathrm{A}}$ was distinct including a lesser effect of mutation within ECL3, and this was most evident for hCT where ECL1 appeared to have an extended role in the functional affinity for this pathway (Figure 12). This likely reflects differences in the coupling pathways downstream of receptor activation by different CT peptides, as has been previously observed. ${ }^{9,10,20}$

The Molecular Control of Efficacy. The efficacy parameter tau from the operational model provides a measure for pathway coupling efficiency relating the number of receptors occupied to response. ${ }^{21}$ Within the TM1 stalk, the effect of alanine mutation on cAMP accumulation efficacy was similar across the CT peptides with an enhancement of efficacy (or trend toward this) seen with residues proximal to the interaction site of $\mathrm{Pro}^{32}-\mathrm{NH}_{2}$ of $\mathrm{sCT}$ in the structure (Figure 13, Table 2). However, mutation of most other residues had no effect. The exception to this was a significant loss of efficacy for hCT with the $\mathrm{Y} 150^{1.41} \mathrm{~A}$ mutant, and a small enhancement of pCT efficacy with the $\mathrm{L} 151^{1.42} \mathrm{~A}$ mutant. The pattern of effect was similar for amylin, but with $\mathrm{V} 147^{1.38} \mathrm{~A}$ and $\mathrm{Y} 149^{1.40} \mathrm{~A}$ exhibiting reduced efficacy within the distal (TM1) residues. The effect on CGRP cAMP efficacy was distinct with most mutations either decreasing efficacy or trending toward lower efficacy. The exception to this was the $\mathrm{N} 130^{\mathrm{ECD}}$ A mutant that, like the other peptides, led to increased efficacy (Figure 13, Table 2). Loss of interaction of the peptide C-terminus with the ECD would be predicted to increase mobility of the ECD and peptide suggesting that receptor-ligand dynamics contribute to the control of cAMP efficacy (presumably affecting Gs coupling). Interestingly, whereas alanine mutagenesis was generally less impactful on sCT binding and function, ECL1 alanine mutation had the greatest impact on 
Table 1. Effect of Single Alanine Mutation in the CTR TM1 Stalk or ECL1 on Binding Affinity (pK $K_{\mathrm{i}}$ ) of CT Peptides Derived from Competition Binding Isotherms, And Receptor Cell Surface Expression ${ }^{a}$

\begin{tabular}{|c|c|c|c|c|c|}
\hline & $\mathrm{sCT} \mathrm{p} K_{\mathrm{i}}$ & $\mathrm{hCT} \mathrm{p} K_{\mathrm{i}}$ & $\mathrm{pCT} \mathrm{p} K_{\mathrm{i}}$ & $\mathrm{sCT}(8-32) \mathrm{p} K_{\mathrm{i}}$ & FACS (\% of WT) \\
\hline WT & $9.57 \pm 0.13(7)$ & $6.97 \pm 0.13(7)$ & $8.08 \pm 0.13(8)$ & $9.20 \pm 0.06$ & $100.0 \pm 3.3(8)$ \\
\hline S129A & $9.15 \pm 0.19(6)$ & $5.72 \pm 0.10^{*}(5)$ & $7.06 \pm 0.12 *(6)$ & $8.44 \pm 0.04 *(5)$ & $160.1 \pm 26.9 *(6)$ \\
\hline N130A & $8.98 \pm 0.20(6)$ & N.D. & $7.32 \pm 0.28^{*}(6)$ & N.D. & $91.0 \pm 18.0(6)$ \\
\hline Y131A & N.D. & N.D. & $7.08 \pm 0.42 *(5)$ & N.D. & $145.4 \pm 18.7 *(4)$ \\
\hline $\mathrm{T} 132 \mathrm{~A}$ & $9.67 \pm 0.06$ & $6.66 \pm 0.21$ & $7.09 \pm 0.18^{*}$ & $8.86 \pm 0.08 *(4)$ & $94.0 \pm 14.4(6)$ \\
\hline M133A & $9.73 \pm 0.11(4)$ & $6.14 \pm 0.07^{*}(5)$ & $6.95 \pm 0.19^{*}(5)$ & $8.99 \pm 0.07$ & $72.7 \pm 11.3(3)$ \\
\hline N135A & N.D. & N.D. & N.D. & N.D. & $118.1 \pm 24.2(6)$ \\
\hline F137A & $9.24 \pm 0.21(6)$ & $6.52 \pm 0.13(5)$ & $6.74 \pm 0.13 *(5)$ & $9.06 \pm 0.07$ & $161.0 \pm 37.0 *(6)$ \\
\hline $\mathrm{T} 138 \mathrm{~A}$ & $9.21 \pm 0.25(5)$ & $6.21 \pm 0.14^{*}(4)$ & $6.94 \pm 0.16^{*}(5)$ & $9.46 \pm 0.10$ & $134.3 \pm 15.0$ \\
\hline P139A & $9.57 \pm 0.13(5)$ & $6.50 \pm 0.10$ & $7.76 \pm 0.06$ & $9.26 \pm 0.07$ & $130.0 \pm 31.3(6)$ \\
\hline E140A & $9.64 \pm 0.10$ & $6.60 \pm 0.07$ & $7.89 \pm 0.10$ & $8.84 \pm 0.10 *$ & $175.4 \pm 22.9 *(6)$ \\
\hline K141A & $9.38 \pm 0.12(5)$ & $6.22 \pm 0.13 *(4)$ & $7.25 \pm 0.10^{*}(4)$ & $8.85 \pm 0.10 *(4)$ & $157.8 \pm 25.5^{*}(6)$ \\
\hline L142A & $9.41 \pm 0.05(4)$ & $6.19 \pm 0.04^{*}(4)$ & $7.24 \pm 0.06^{*}(4)$ & $8.39 \pm 0.07 *(4)$ & $158.4 \pm 18.8^{*}(6)$ \\
\hline N144A & $9.47 \pm 0.10$ & $6.46 \pm 0.06$ & $7.84 \pm 0.04$ & $9.05 \pm 0.11$ & $157.0 \pm 31.7 *(6)$ \\
\hline Y146A & $8.98 \pm 0.32(5)$ & $5.78 \pm 0.14^{*}(5)$ & $7.43 \pm 0.14$ & $7.96 \pm 0.13 *$ & $162.9 \pm 18.6^{*}(6)$ \\
\hline V147A & $9.66 \pm 0.04(4)$ & $6.58 \pm 0.10(5)$ & $7.94 \pm 0.15(5)$ & $9.13 \pm 0.05(4)$ & $152.6 \pm 18.9 *(6)$ \\
\hline L148A & $9.41 \pm 0.27(5)$ & $5.75 \pm 0.22 *(5)$ & $7.16 \pm 0.13 *(5)$ & $8.67 \pm 0.14 *(5)$ & $77.2 \pm 9.3(6)$ \\
\hline Y149A & $9.60 \pm 0.07(4)$ & $5.18 \pm 0.21 *(5)$ & $7.32 \pm 0.07 *$ & $8.72 \pm 0.09 *(4)$ & $140.7 \pm 33.1 *(6)$ \\
\hline Y150A & $9.60 \pm 0.06(4)$ & $5.99 \pm 0.06^{*}(4)$ & $7.55 \pm 0.06$ & $8.48 \pm 0.04 *(4)$ & $165.7 \pm 46.9 *(6)$ \\
\hline L151A & $9.59 \pm 0.06(4)$ & $6.27 \pm 0.04 *(5)$ & $7.92 \pm 0.08(5)$ & $8.73 \pm 0.05 *(4)$ & $92.9 \pm 6.3(6)$ \\
\hline WT & $9.73 \pm 0.07(5)$ & $6.78 \pm 0.21$ & $7.83 \pm 0.18(5)$ & $9.20 \pm 0.12(5)$ & $100 \pm 2.0(6)$ \\
\hline H201A & $9.41 \pm 0.22(4)$ & $6.53 \pm 0.09$ & $8.20 \pm 0.12(4)$ & $9.27 \pm 0.22(4)$ & $74.5 \pm 15.2^{*}(4)$ \\
\hline L202A & $9.45 \pm 0.06$ & $5.75 \pm 0.36^{*}(5)$ & $7.50 \pm 0.16$ & $8.87 \pm 0.10$ & $176.4 \pm 38.5 *$ \\
\hline V203A & $9.60 \pm 0.07$ & $6.46 \pm 0.19$ & $7.55 \pm 0.17$ & $8.99 \pm 0.12(4)$ & $120.9 \pm 21.6$ \\
\hline E204A & $9.55 \pm 0.17(4)$ & $6.69 \pm 0.18$ & $7.79 \pm 0.11$ & $9.26 \pm 0.09$ & $133.9 \pm 17.8$ \\
\hline V205A & $9.62 \pm 0.16(4)$ & $6.14 \pm 0.38$ & $6.66 \pm 0.17 *(5)$ & $8.27 \pm 0.22 *(5)$ & $138.5 \pm 28.2$ \\
\hline N208A & $9.52 \pm 0.09$ & $6.44 \pm 0.15$ & $7.02 \pm 0.13$ & $8.81 \pm 0.22$ & $104.4 \pm 25.4$ \\
\hline G209A & $9.60 \pm 0.11$ & $6.46 \pm 0.22$ & $7.79 \pm 0.16$ & $9.01 \pm 0.17(4)$ & $159.9 \pm 10.2 *(4)$ \\
\hline E210A & $9.39 \pm 0.19$ & $6.89 \pm 0.08$ & $7.69 \pm 0.12$ & $8.89 \pm 0.26$ & $114.2 \pm 15.1$ \\
\hline L211A & $9.66 \pm 0.09$ & $5.92 \pm 0.16$ & $6.94 \pm 0.04$ & $8.78 \pm 0.19$ & $99.5 \pm 13.4(4)$ \\
\hline $\mathrm{V} 212 \mathrm{~A}$ & $9.70 \pm 0.06(4)$ & $6.32 \pm 0.17$ & $7.89 \pm 0.10$ & $9.25 \pm 0.20$ & $184.3 \pm 29.1 *$ \\
\hline $\mathrm{R} 213 \mathrm{~A}$ & $9.74 \pm 0.18$ & $6.41 \pm 0.29$ & $7.52 \pm 0.30$ & $8.98 \pm 0.11(4)$ & $123.0 \pm 18.3$ \\
\hline $\mathrm{R} 214 \mathrm{~A}$ & $9.65 \pm 0.09(4)$ & $7.15 \pm 0.18$ & $7.76 \pm 0.16(4)$ & $9.28 \pm 0.12(4)$ & $145.9 \pm 26.1$ \\
\hline D215A & $9.51 \pm 0.08$ & $6.12 \pm 0.10$ & $7.39 \pm 0.17(4)$ & $8.73 \pm 0.07(4)$ & $102.1 \pm 18.6$ \\
\hline P216A & $9.58 \pm 0.05(4)$ & $6.14 \pm 0.11$ & $7.43 \pm 0.12(4)$ & $8.88 \pm 0.14(4)$ & $165.8 \pm 18.0^{*}$ \\
\hline V217A & $9.54 \pm 0.05(4)$ & $6.81 \pm 0.19$ & $7.85 \pm 0.11$ & $9.32 \pm 0.21$ & $107.6 \pm 29.0$ \\
\hline S218A & $9.44 \pm 0.05(4)$ & $6.28 \pm 0.23(5)$ & $7.55 \pm 0.11$ & $9.06 \pm 0.13$ & $193.6 \pm 24.9 *$ \\
\hline C219A & N.D. & N.D. & N.D. & N.D. & $16.9 \pm 6.4^{*}(4)$ \\
\hline
\end{tabular}

${ }^{a} \mathrm{p} K_{\mathrm{i}}$ values were derived for each ligand and mutant receptor from analysis of either homologous (sCT(8-32)) or heterologous (sCT, hCT, $\mathrm{pCT}$ ) competition of [125]I-sCT(8-32) binding. Cell surface receptor expression was determined by FACS using an anti-c-myc antibody, and normalized to WT expression and expressed as \%WT. All values are mean \pm S.E.M. (independent " $n$ " values are indicated within parentheses). Significance of changes in receptor expression, or $\mathrm{p} K_{\mathrm{i}}$ of each ligand, was determined by comparison of mutant receptors to WT values by a one-way ANOVA and Dunnett's post-test $(p<0.05$ represented by an asterisk $(*))$. N.D. denotes affinity not determined as robust radioligand binding was not detected.

sCT-mediated cAMP efficacy with significantly decreased efficacy seen for $\mathrm{E} 204^{2.70} \mathrm{~A}, \mathrm{~V} 206^{\mathrm{ECL} 1} \mathrm{~A}, \mathrm{P} 207^{\mathrm{ECL} 1} \mathrm{~A}$, $\mathrm{G} 209^{\mathrm{ECL} 1} \mathrm{~A}, \mathrm{~V} 212^{\mathrm{ECL} 1} \mathrm{~A}, \mathrm{R} 214^{\mathrm{ECL} 1} \mathrm{~A}, \mathrm{P} 216^{3.26} \mathrm{~A}$, and $\mathrm{S} 218^{3.28} \mathrm{~A}$. Of note, within ECL1 only $\mathrm{H} 201^{2.67}$ and $\mathrm{V} 205^{\mathrm{ECL} 1}$ are in direct contact with sCT (Figure 6D), implying that ECL1 is likely to be important for propagation of conformational change linked to cAMP (Gs) efficacy for this peptide. For hCT, the distal $\mathrm{V} 212^{\mathrm{ECL} 1} \mathrm{~A}, \mathrm{R} 214^{\mathrm{ECL} 1} \mathrm{~A}$, and $\mathrm{S} 218^{3.28} \mathrm{~A}$ also impacted cAMP efficacy, as well as $\mathrm{L} 202^{2.68} \mathrm{~A}$. Both $\mathrm{V} 212^{\mathrm{ECL} 1} \mathrm{~A}$ and $\mathrm{R} 214^{\mathrm{ECL} 1} \mathrm{~A}$ were also important for pCT efficacy, with only $\mathrm{P} 207^{\mathrm{ECL} 1} \mathrm{~A}$ achieving significance for reduced efficacy (Figure 13, Table
2). ECL1 alanine mutations had lesser overall impact on amylin and CGRP efficacy with only $\mathrm{L} 202^{2.68} \mathrm{~A}$ (both peptides), V212 ${ }^{\mathrm{ECL} 1} \mathrm{~A}$ (amylin) and $\mathrm{P} 216^{3.26} \mathrm{~A} / \mathrm{Ser} 218^{3.28} \mathrm{~A}$ (CGRP) causing significant reductions in efficacy (Figure 13, Table 2).

As described above, the weak pERK response meant that only a limited subset of mutants could be robustly fitted with the operational model for amylin and CGRP (Table 3). For the CT peptides, the pattern of effect of alanine mutation on pERK efficacy was generally distinct from that observed for cAMP efficacy (Figures 13-15, Table 3). Loss of efficacy was 

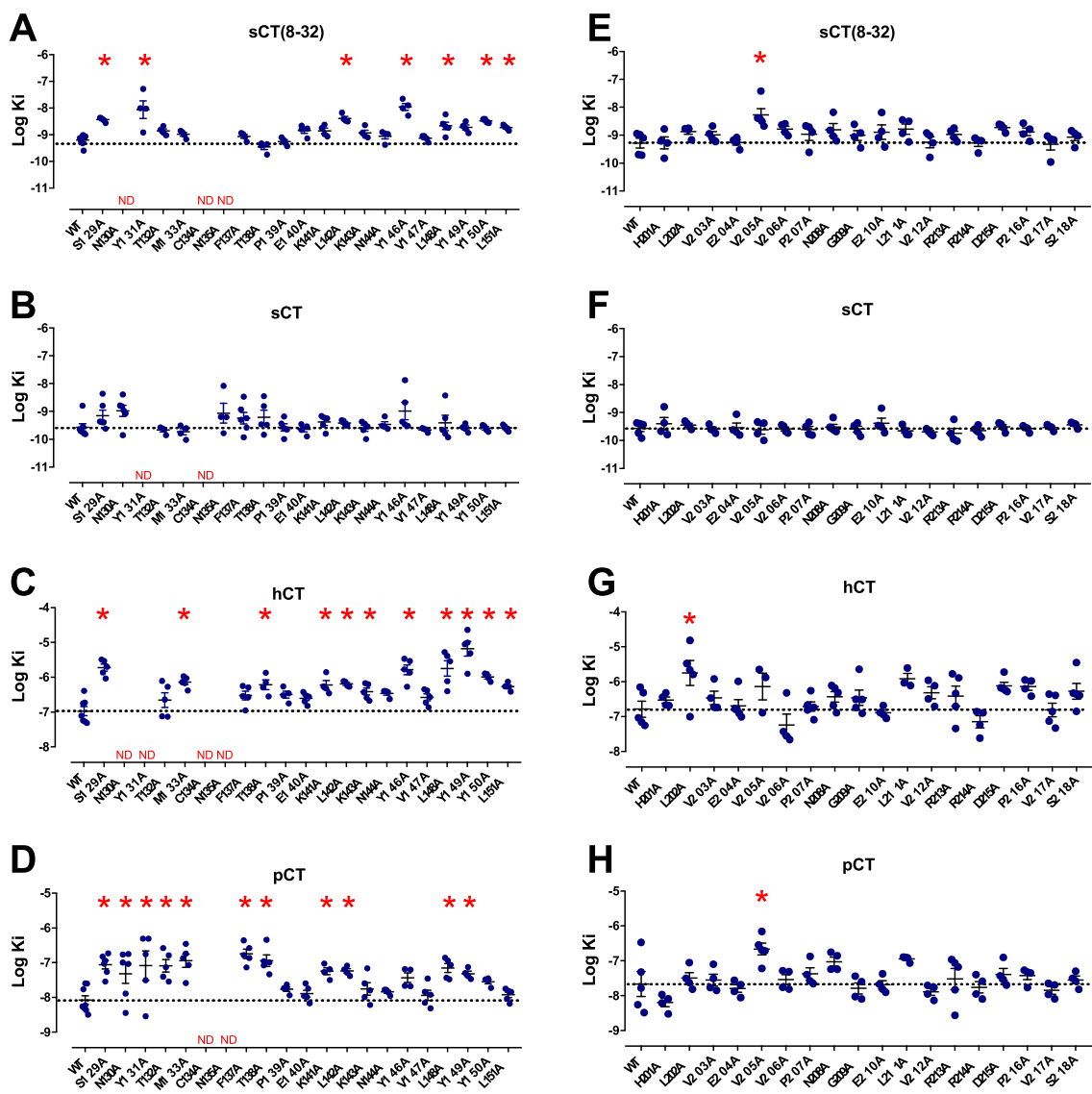

Figure 8. Alanine mutation of the TM1 stalk and ECL1 of the CTR selectively alters peptide affinity. For each receptor mutant and ligand, competition binding curves were established and $\log K_{\mathrm{i}}$ determined: (A) effect of TM1 stalk mutants on sCT $\mathrm{S}_{(8-32)} \log \mathrm{K}_{\mathrm{i}}$ (B) effect of TM1 stalk mutants on sCT $\log \mathrm{K}_{\mathrm{i}}$; (C) effect of TM1 stalk mutants on hCT $\log \mathrm{K}_{\mathrm{i}}$ (D) effect of TM1 stalk mutants on pCT log $K_{\mathrm{i}}$; (E) effect of ECL1 mutants on $\mathrm{sCT}_{(8-32)} \log \mathrm{K}_{\mathrm{i}}$; $(\mathrm{F})$ effect of ECL1 mutants on sCT $\log \mathrm{K}_{\mathrm{i}} ;(\mathrm{G})$ effect of ECL1 mutants on hCT log $\mathrm{K}_{\mathrm{i}}$ ( $\left.\mathrm{H}\right)$ effect of ECL1 mutants on pCT $\log \mathrm{K}_{\mathrm{i}}$. Significance of changes was established by comparison of the WT to the other receptor mutants in a one-way ANOVA and Dunnett's post-test to determine $\log K_{\mathrm{i}}$ values with significant changes $(P<0.05)$ denoted by an asterisk $(*)$. N.D., functional affinity not determined. Individual " $n$ " values are shown. The dotted line is the WT mean.

observed for $\mathrm{N} 130^{\mathrm{ECD}} \mathrm{A}$ for all peptides and $\mathrm{Y} 131^{\mathrm{ECD}} \mathrm{A}$ for $\mathrm{sCT}$ and pCT. There was loss of efficacy of the $\mathrm{T} 138^{1.29} \mathrm{~A}$ mutant for $\mathrm{sCT}$ and hCT but not $\mathrm{pCT}$, and of $\mathrm{E} 140^{1.31} \mathrm{~A}$ for sCT and pCT, whereas there was increased hCT efficacy of this mutant, together with selective enhancement of hCT efficacy with P139 $9^{1.30}$ A. Similarly, there was enhanced efficacy for K $141^{1.32}$ A and $\mathrm{L} 142^{1.33} \mathrm{~A}$ for sCT and pCT, with no effect on hCT efficacy. In the distal segment, peptide-specific effects were observed although the trend for pCT followed that of $\mathrm{sCT}$ with enhanced efficacy for $\mathrm{Y} 146^{1.37} \mathrm{~A}$ (trend for $\mathrm{pCT}$ ) and $\mathrm{V} 147^{1.38} \mathrm{~A}$ and decreased efficacy for $\mathrm{L} 151^{1.42} \mathrm{~A}$ (trend for $\mathrm{pCT}$ ). The effect of mutation was distinct for hCT with decreased efficacy for $\mathrm{Y} 146^{1.37} \mathrm{~A}$ (and a trend toward a decrease for $\mathrm{V} 147^{1.38} \mathrm{~A}$ ). There was also selective increased efficacy of $\mathrm{L} 148^{1.39} \mathrm{~A}$ and decreased efficacy of $\mathrm{Y} 149^{1.40} \mathrm{~A}$ for hCT (Figure 14, Table 3). Within ECL1, there was increased efficacy of $\mathrm{E} 204^{2.70} \mathrm{~A}$ and $\mathrm{R} 213^{\mathrm{ECL} 1} \mathrm{~A}$ for all peptides, with selectively increased efficacy of $\mathrm{D} 215^{3.25} \mathrm{~A}$ and $\mathrm{V} 217^{3.27} \mathrm{~A}$ for hCT, and $\mathrm{H} 201^{2.67} \mathrm{~A}$ and $\mathrm{E} 210^{\mathrm{ECL} 1} \mathrm{~A}$ for $\mathrm{pCT}$. For all three peptides, there was a trend toward decreased efficacy of the $\mathrm{V} 205^{\mathrm{ECL} 1} \mathrm{~A}$ mutant, but this was only significant for hCT (Figure 14, Table 3).

Mapping of all alanine mutants of the extracellular surface of the CTR on peptide efficacy revealed both commonalities and distinctions in how peptides engage with the receptor and propagate efficacy (Figure 15). As reported previously, ${ }^{11}$ mutations of residues in the core of ECL2 that contribute to packing of this loop have a general effect to enhance cAMP efficacy, likewise for the CT peptides and amylin, there is a common effect to increase efficacy of mutants within the ECD proximal to $\mathrm{SCT}$ Pro32- $\mathrm{NH}_{2}$ in the structure, and also in the proximal end of ECL3 deep within TM6. In distinction to the other peptides, $\mathrm{pCT}$ exhibited increased efficacy with mutations that lined the TM1/TM7 interface and contrasted to the loss of functional affinity observed for this pathway for most of these mutants (Figures 12 and 15). Interestingly, mutation of ECL1 led to decreased cAMP efficacy, with greatest impact on sCT. Overall, with the exception of ECL1, the surface residues of the CTR act to constrain the activation of receptor for "Gs" coupling. Of note, a significant portion of ECL1 could not be modeled into the EM map due to lack of robust density, indicating that it has greater mobility than the rest of the receptor, potentially caused by lack of significant direct interactions with the peptide. For the purpose of mutation mapping, this segment of the receptor was modeled based on ECL1 of the CGRP receptor that forms a short $\alpha$ helix ${ }^{15}$ and disruption of secondary structure of this loop could potentially contribute to the negative effects on cAMP efficacy observed for the CT peptides. Intriguingly, deletion of $\mathrm{V} 205^{\mathrm{ECL} 1}$ within ECL1 of CLR causes marked loss of function 

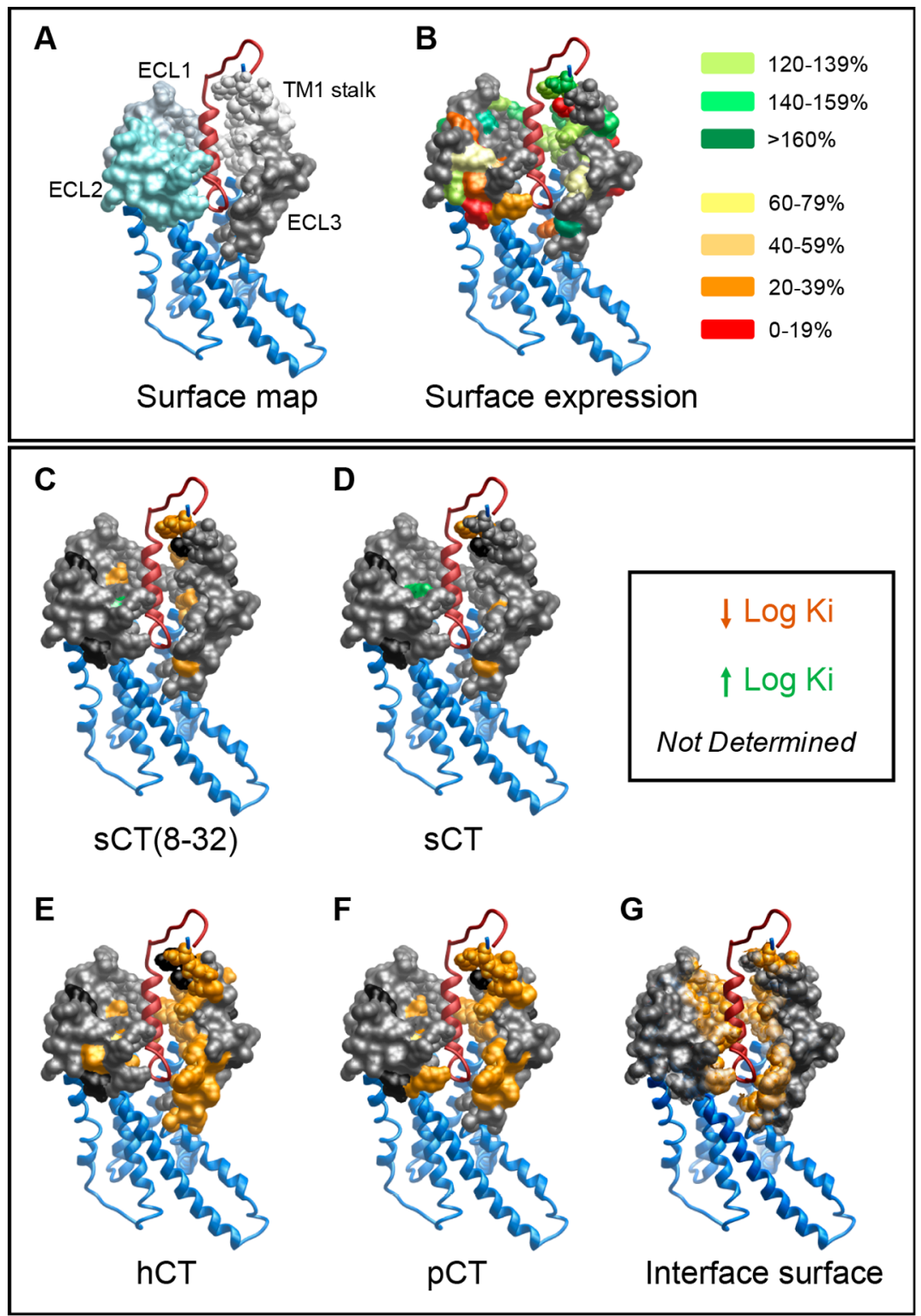

Figure 9. Identification of key amino acids of the CTR extracellular surface for peptide binding affinity $\left(\log K_{\mathrm{i}}\right)$ : (A) top view of the active, sCTbound, CTR model with the extracellular surface subject to alanine scanning depicted in gray (combined surface/cpk representation); (B) effect of mutation on cell surface receptor expression; $(\mathrm{C}-\mathrm{D}, \mathrm{F})$ effect of mutation on CT peptide affinity $\left(\log K_{\mathrm{i}}\right)$; (C) $\mathrm{sCT}_{(8-32)}$; (D) sCT; (E) hCT; (F) pCT. Mutations that significantly alter peptide affinity are colored dark orange for decreased $\log K_{\mathrm{i}}$, and green for increased log $K_{i}$, with mutated amino acids without significant alteration to $\log K_{\mathrm{i}}$ colored gray. $\mathrm{sCT}$ is shown as dark red, in ribbon representation. Amino acid mutations where there was an insufficiently robust functional effect to quantify by radioligand competition binding are depicted in black. (G) Illustration of the interaction surface for $\mathrm{sCT}$ (dark orange). The receptor ECD is not shown for clarity.

for the adrenomedullin (CLR:RAMP2) receptor, ${ }^{22}$ and this would be consistent with the importance of maintenance of secondary structure within ECL1.

In general, there were parallels between the effect of alanine mutation on CT peptide cAMP efficacy and that observed for amylin, albeit that there was more limited impact for the latter. In contrast, the effect on CGRP-dependent cAMP efficacy was generally distinct and this was evident for the mutations to the TM1 stalk (Figures 13 and 15) and previously published data on ECL $3^{11}$. In the recently solved CGRP receptor structure, the CLR ECD has a different orientation to that of the CTR, but the CGRP peptide C-terminal Phe37-NH2 is located in a spatially equivalent position to the sCT C-terminus, ${ }^{15}$ where it interacts with residues at the RAMP1:CLR ECD interface rather than the extension of the TM1 stalk that is observed for $\mathrm{sCT}$. This may account for at least some of the differences in the impact of mutation to the CTR TM1 stalk on CGRP versus other peptide binding.

Remarkably, with minor exception, the effect of mutation of pERK efficacy was "globally" in the opposite direction when compared to cAMP (Figure 15), albeit that the specific residues contributing enhanced or diminished efficacy were not necessarily equivalent. This is clearly seen for the effect of ECL1 mutation, and in the distinct patterns of effect on pERK and cAMP efficacy for pCT and hCT (Figure 15). This suggests that the drivers of cAMP formation (presumptively Gs) and pERK are quite distinct and appear to be associated with mutually exclusive conformations/conformational dynam- 


\section{$\log \mathrm{K}_{\mathrm{A}} \mathrm{CAMP}$}
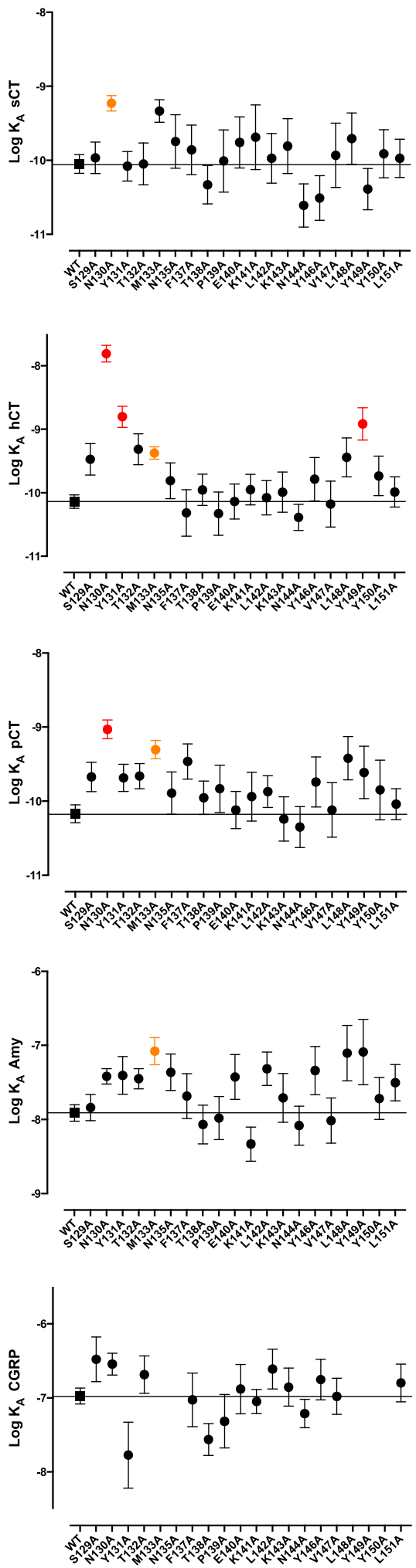
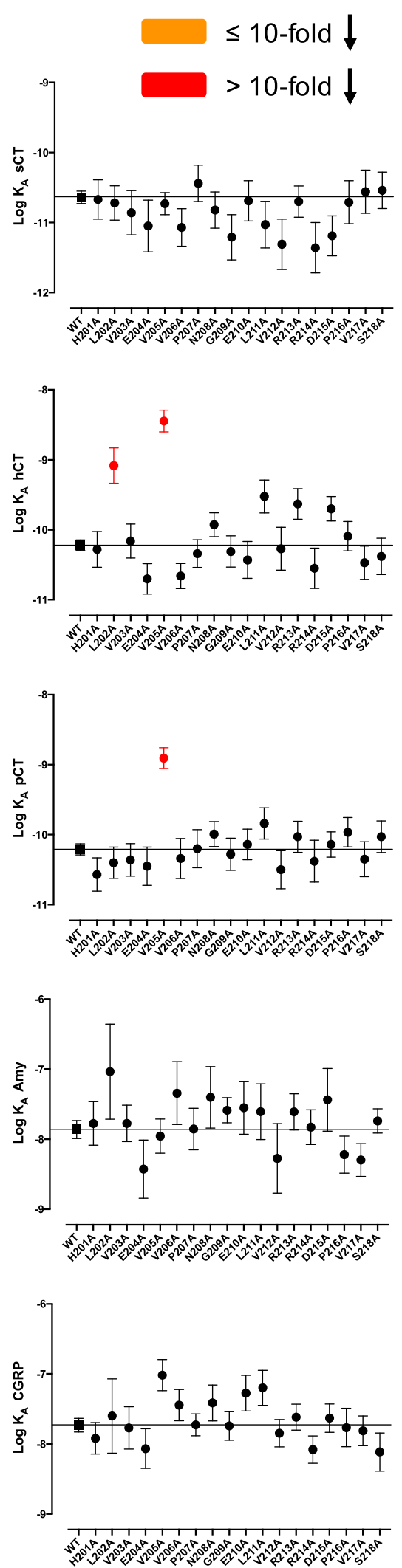

Figure 10. Alanine mutation of the TM1 stalk and ECL1 of the CTR alters cAMP functional affinity $\left(\log K_{\mathrm{A}}\right)$ in a peptide- and pathway-specific manner. Functional affinities derived from operational fitting of concentration-response curves in cAMP accumulation for alanine mutation of the TM1 stalk (LHS) and ECL1 (RHS) are displayed as Log $\mathrm{K}_{\mathrm{A}}$. Significance of changes was established by comparison of the WT to the other receptor mutants following one-way ANOVA and Dunnett's post-test with $P<0.05$ accepted as significant. Mutants that gave significant reductions between 3 - and 10 -fold are colored orange, and those with reductions greater than 10 -fold colored red. Where data were insufficiently robust to derive a reliable value for $\log K_{\mathrm{A}}$ no symbol is shown. 


\section{Log $K_{A} p E R K$}
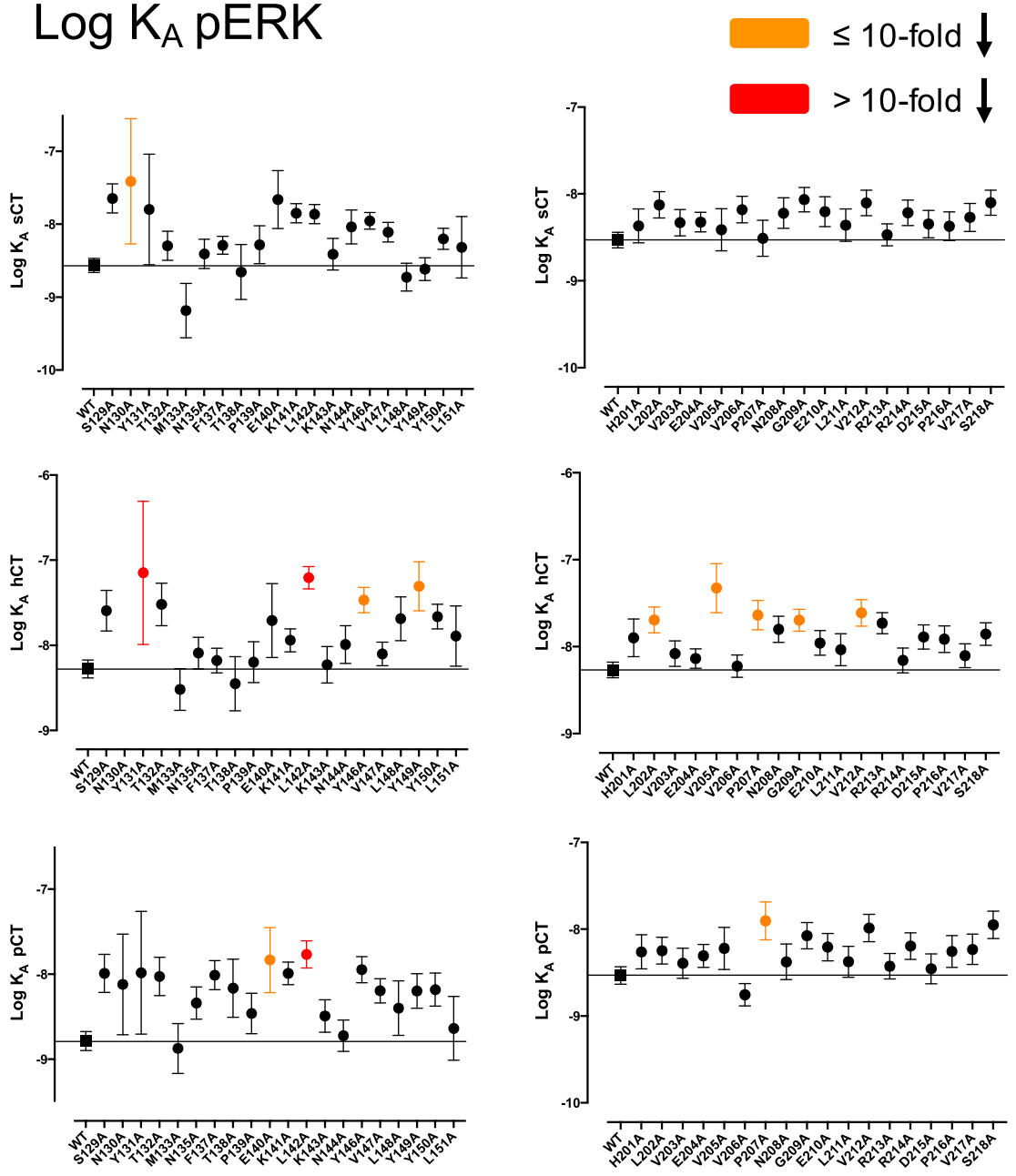

Figure 11. Alanine mutation of the TM1 stalk and ECL1 of the CTR alters pERK functional affinity $\left(\log K_{\mathrm{A}}\right)$ in a peptide- and pathway-specific manner. Functional affinities derived from operational fitting of concentration-response curves in pERK for alanine mutation of the TM1 stalk (LHS) and ECL1 (RHS) are displayed as Log $\mathrm{K}_{\mathrm{A}}$. Significance of changes was established by comparison of the WT to the other receptor mutants following one-way ANOVA and Dunnett's post-test with $P<0.05$ accepted as significant. Mutants that gave significant reductions between 3- and 10 -fold are colored orange, and those with reductions greater than 10-fold are colored red. Where data were insufficiently robust to derive a reliable value for $\log K_{\mathrm{A}}$ no symbol is shown.

ics. Previous analysis of pathways linked to pERK for hCT provides support for this hypothesis, whereby pERK was independent of protein kinase $A$ and $G_{i / o}$ pertussis toxin sensitive $G$ proteins, but could be diminished by inhibition of phospholipase $\mathrm{C}$ and protein kinase $\mathrm{C} .{ }^{20}$ Unlike the GLP-1R, where $\beta$-arrestins are a significant contributor to $\mathrm{pERK},{ }^{24}$ the native hCTR does not recruit arrestin, ${ }^{9}$ and as such the distinct pattern of effects on pERK are independent of $\beta$-arrestins.

Another striking feature of the pattern of effect of mutation on CT peptide efficacy is the major differences between the CTR and the related class B GPCR GLP-1R for which equivalent alanine scanning mutagenesis and operational analysis have been completed. ${ }^{23}$ For this receptor, ECL2 is a major determinant of cAMP (Gs) signaling and mutation markedly attenuates peptide efficacy. ${ }^{23,24}$ Although this distinction has been noted previously, ${ }^{11}$ the CTR ECL2 was modeled with distinct packing and $\mathrm{W} 290^{\mathrm{ECL} 2}$ was modeled toward the peptide. ${ }^{1,11}$ The improved resolution obtained in the current study has enabled this loop to be accurately modeled for the first time, and it exhibits similar packing of the $\mathrm{W} 290^{\mathrm{ECL} 2}$ and $\mathrm{R} 281^{4.64}$ residues to that observed in the GLP$1 \mathrm{R}$ structure. The closest homologue of the CTR is the CLR and there is very similar packing observed for ECL2 of both these receptors (Figure 6). While equivalent analysis to separate functional affinity and efficacy has not been performed on the CLR, alanine mutation of CLR in the context of the complex with RAMP1 to form the CGRP receptor is clearly associated with a loss of potency and/or $E_{\max }$ in cAMP signaling, ${ }^{15}$ even where expression is not changed. This suggests that ECL2 of CLR may have a more similar role to that of the GLP-1R than the more closely related CTR. Nonetheless, like CLR, the CTR can interact with each of the 3 RAMPs to form different amylin receptors. ${ }^{4}$ It is unclear if this would alter the role of ECL2 in propagation of conformational change linked to Gs coupling; however, in the CGRP:CLR:RAMP1:Gs structure, ECL2 of the CLR is partially stabilized by interactions of RAMP $1 .^{15}$ Mutations within ECL2 of CLR have distinct effects on cAMP production in the presence of different RAMPs, supporting the idea that ECL2 is capable of influencing Gs coupling ${ }^{25}$ and that the importance of this domain for the CTR family of receptors may be dependent on the receptor/RAMP combination. 


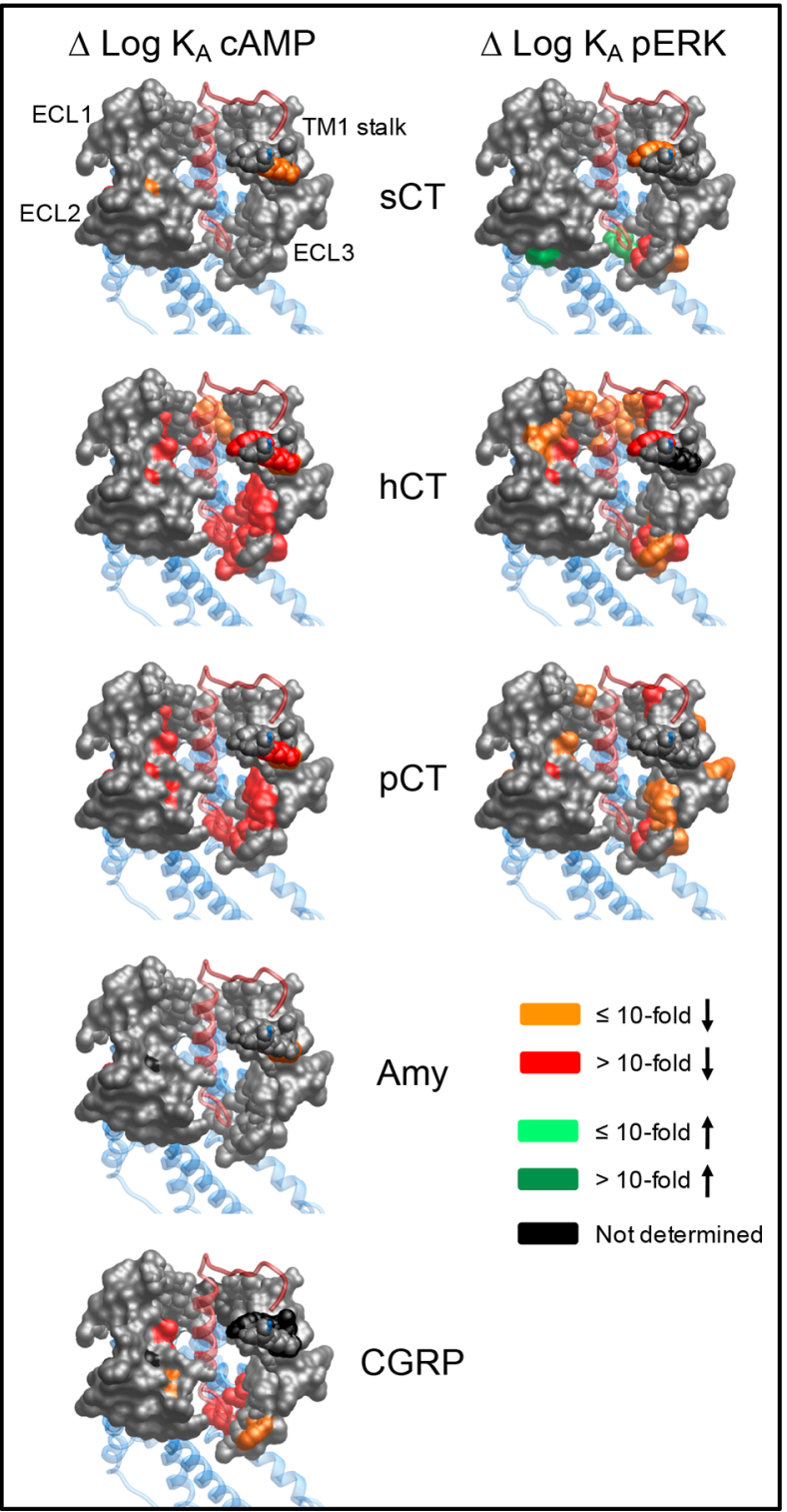

Figure 12. Alanine mutation of the extracellular surface of the CTR alters functional affinity $\left(\log K_{\mathrm{A}}\right)$ in a peptide- and pathway-specific manner. Functional affinities derived from operational fitting of concentration-response curves in cAMP accumulation (LHS) and pERK (RHS) are displayed as $\Delta \log \mathrm{K}_{\mathrm{A}}$ from wild-type. Illustrated is a top view of the active, sCT-bound, CTR model with the extracellular surface subject to alanine scanning depicted (combined surface/cpk representation). Mutations that significantly alter peptide functional $\log K_{\mathrm{A}}$ are colored according to the magnitude of effect, with mutated amino acids without significant alteration to $\log K_{\mathrm{A}}$ colored gray. sCT is shown as dark red, in ribbon representation. Amino acid mutations where there was an insufficiently robust functional effect to quantify by operational modeling are depicted in black. The receptor ECD is not shown for clarity.

\section{CONCLUSION}

In this study the enhanced resolution of the sCT:CTR:Gs structure has provided novel insights into the importance of the extracellular surface of the CTR in peptide-mediated binding and pathway-specific efficacy. It has confirmed the conservation of secondary structural elements of the ECL2 and highlighted distinctions in how different, related class B GPCRs may be activated. New mutational data on the TM1

\section{$\log \mathrm{Tau}_{\mathrm{c}} \mathrm{cAMP}$ \\ $\begin{array}{ll}\leq 10 \text {-fold } \downarrow & \leq 10 \text {-fold } \uparrow \\ >10 \text {-fold } \downarrow & >10 \text {-fold } \uparrow\end{array}$}

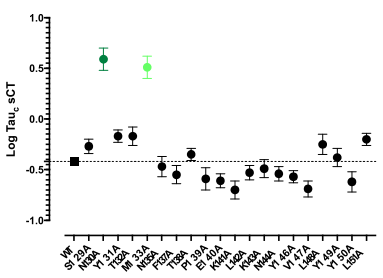
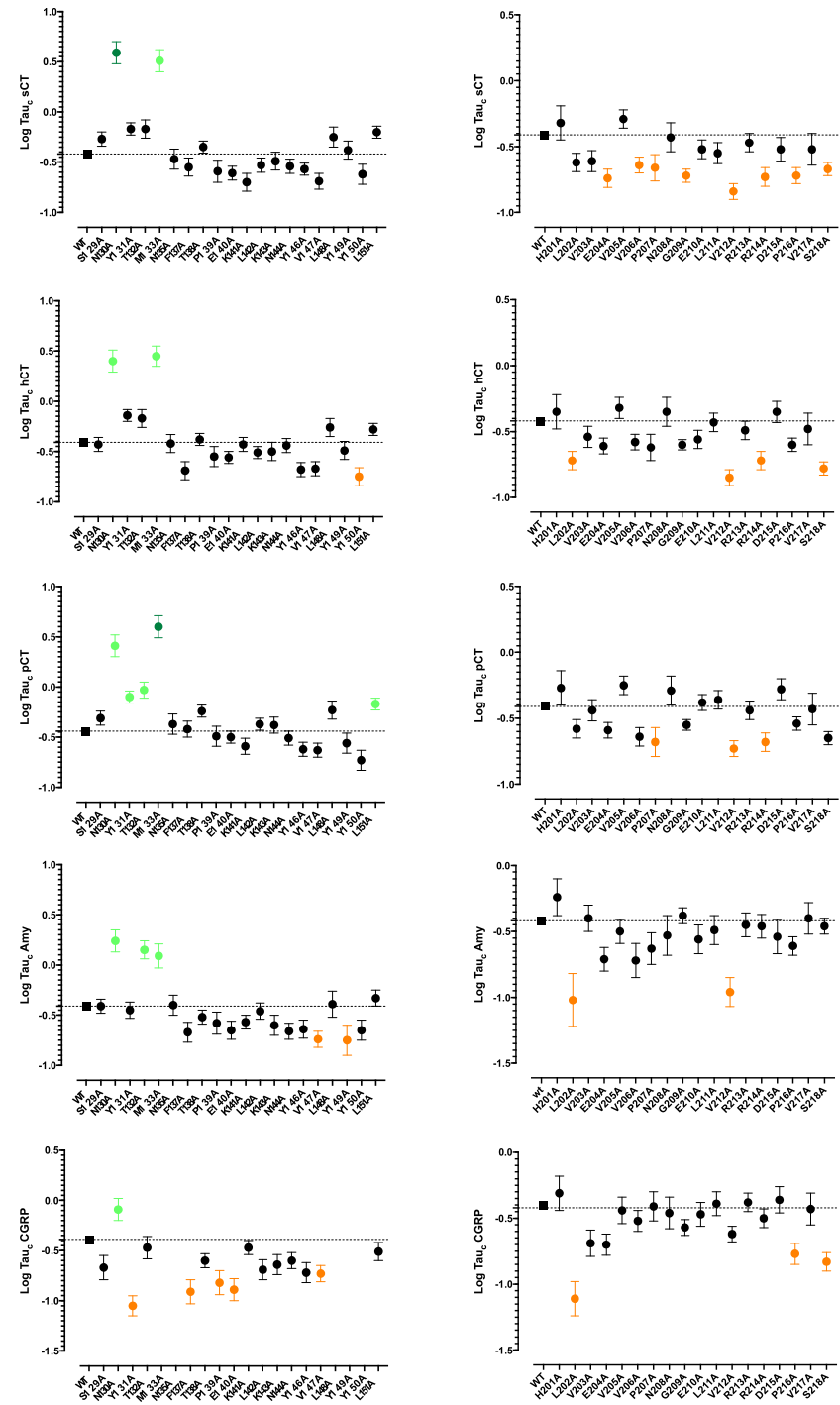

Figure 13. Alanine mutation of the TM1 stalk and ECL1 of the CTR alters peptide efficacy in cAMP accumulation assays. Efficacy (log tau) was derived from operational fitting of concentration-response curves in cAMP accumulation for alanine mutation of the TM1 stalk (LHS) and ECL1 (RHS) and are displayed as Log $\mathrm{Tau}_{\mathrm{c}}$, where calculated log tau values were corrected for changes to receptor cell surface expression to give $\log \operatorname{tau}_{\mathrm{c}}$. Significance of changes to peptide efficacy was established by comparison of the WT to the other receptor mutants following one-way ANOVA and Dunnett's post-test with $P<$ 0.05 accepted as significant. Mutants that gave significant reductions between 3- and 10-fold are colored orange, and those with reductions greater than 10 -fold colored red. Mutants that gave significant enhancements to efficacy between 3- and 10-fold are colored light green and those that enhanced efficacy $>10$-fold in dark green. Where data were insufficiently robust to derive a reliable value for log tau no symbol is shown.

stalk and ECL1 have also offered new knowledge of the distinct control of cAMP versus pERK signaling. Collectively, these data in conjunction with previous mutagenesis data have presented evidence that the conformations linked to the different signaling pathways are, in many ways, mutually exclusive. This work furthers our understanding of the complex 

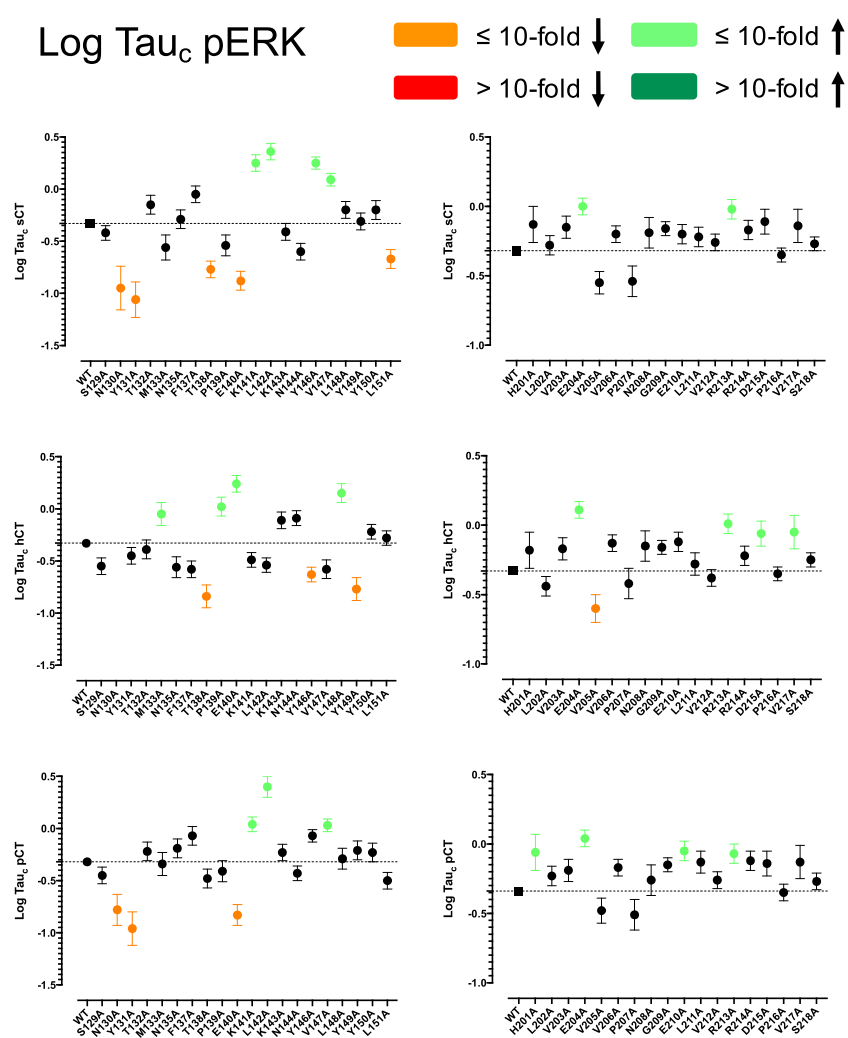

Figure 14. Alanine mutation of the TM1 stalk and ECL1 of the CTR alters peptide efficacy in pERK assays. Efficacy (log tau) was derived from operational fitting of concentration-response curves in $p E R K$ assays for alanine mutation of the TM1 stalk (LHS) and ECL1 (RHS), and are displayed as Log $\mathrm{Tau}_{\mathrm{c}}$, where calculated log tau values were corrected for changes to receptor cell surface expression to give $\log \operatorname{tau}_{\mathrm{c}}$. Significance of changes to peptide efficacy was established by comparison of the WT to the other receptor mutants following oneway ANOVA and Dunnett's post-test with $P<0.05$ accepted as significant. Mutants that gave significant reductions between 3- and 10 -fold are colored orange. Mutants that gave significant enhancements to efficacy between 3- and 10-fold are colored light green. Where data were insufficiently robust to derive a reliable value for log tau no symbol is shown.

nature of signaling elicited by GPCRs and, in particular, that of the therapeutically important class B1 GPCR subfamily.

\section{METHODS}

Reagents. All peptides were purchased from Mimotopes. Dulbecco's Modified Eagle's Medium (DMEM) was purchased from Invitrogen. Foetal bovine serum (FBS) was purchased from Thermo Fisher Scientific. AlphaScreen reagents, Lance cAMP kit, and 384-well Optiplates were purchased from PerkinElmer. SureFire ERK1/2 reagents were obtained from TGR Biosciences and PerkinElmer. IP-One HTRF assay kit was from CisBio. Antibodies were purchased from $R \& D$ Systems and ThermoFisher. All other reagents were purchased from Sigma-Aldrich or BDH Merck and were of an analytical grade.

Mutagenesis. Desired mutations were introduced to $\mathrm{N}$ terminally c-Myc tagged human CTR in pENTER11 (Invitrogen) via the Q5 High-Fidelity PCR Kit (New England Biolabs), then LR recombination reactions were conducted to transfer mutated and wild-type (WT) receptors into the pEF5/ FRT/V5-DEST destination vector using Gateway Technology
(Invitrogen). The oligonucleotides for mutagenesis were purchased from Bioneer Pacific, and mutants were confirmed by automated-sequencing.

Stable Cell Line Generation and Cell Culture. The mutant or wild-type (WT) receptor genes were integrated into FlpIn-CV1 cells using Flp-In system (Invitrogen). Stable FlpIn expression cell lines were generated through polyclonal selection, screening and maintained in DMEM supplemented with $5 \%(\mathrm{v} / \mathrm{v}) \mathrm{FBS}, 300 \mu \mathrm{g} / \mathrm{mL}$ hygromycin B (Invitrogen) at $37{ }^{\circ} \mathrm{C}$ in $5 \% \mathrm{CO}_{2}$. Independent WT controls were established in parallel for the TM1 stalk and ECL1 mutants.

Whole Cell Competition Binding Assays. Radioligand competition binding was performed as previously described $^{10,11}$ on whole cells seeded into 96-well plates and cultured overnight. For homologus competition binding experiments, cells were incubated overnight at $4{ }^{\circ} \mathrm{C}$ with $\sim 100 \mathrm{pM}^{125} \mathrm{I}_{-\mathrm{sCT}}{ }_{(8-32)}$ (specific activity, $2000 \mathrm{Ci} / \mathrm{mmol}$ ) and serial dilutions of noniodinated $\mathrm{sCT}_{(8-32)}$. For heterologous competition binding assays, cells were incubated overnight with the antagonist radioligand ${ }^{125} \mathrm{I}_{-} \mathrm{sCT}_{(8-32)}$, and serial dilutions of competing unlabeled peptide. Nonbound ligand was removed and bound ligand activity was measured using a $\gamma$ counter (Wallac Wizard 1470 Gamma Counter, PerkinElmer, $78 \%$ counter efficiency). Values were normalized against nonspecific binding, defined by the presence of $1 \mu \mathrm{M}$ of unlabeled $\mathrm{sCT}_{(8-32)}$, and total ligand bound radioligand.

Cell Surface Expression by FACS. Surface expression of c-Myc tagged CTR mutants stably expressed in CV-1 cells was quantified by flow cytometry using standard methods. Cells were grown in 6 -well plates at $\sim 5 \times 10^{5}$ cells per well the day before assay. Cells were harvested in the presence of versene. All staining steps were conducted in ice cold Hank's Balanced Salt Solution (HBSS) with $0.1 \%$ bovine serum albumin (BSA) and $20 \mathrm{mM}$ HEPES (4-(2-hydroxyethyl)-1-piperazineethanesulfonic acid, $\mathrm{pH}$ 7.4). Blocking was conducted in 5\% BSA. Primary antibody staining was performed with $5 \mu \mathrm{g} / \mathrm{mL}$ 9E10 (anti-c-Myc) antibody. The secondary antibody was $1 \mu \mathrm{g} / \mathrm{mL}$ goat antimouse AF647 (ThermoFisher). Sytox blue was used for live/dead discrimination. Data were collected on a FACS CantosII (BD Biosciences) with at least 20000 live cells collected per sample. WT stained CTR sample and stained parental CV-1 cells were collected at the beginning and the end of each run. Data were analyzed using FlowJo. The mean AF647 fluorescence intensity from each sample for a particular experiment was normalized against parental (0\%) and WT CTR (100\%) controls.

cAMP Accumulation Assay. Cells $\left(2.5 \times 10^{4}\right.$ cells/well $)$ were seeded into 96-well plates and incubated overnight. Cells were stimulated with increasing concentrations of ligands for $30 \mathrm{~min}$ in the presence of $0.5 \mathrm{mM}$ 3-isobutyl-1-methylxanthine (IBMX). The liquid was discarded, changed to absolute ethanol and volatilized to dryness at room temperature. Samples were then lysed and intracellular cAMP was detected using the PerkinElmer Lance kit as previously described. ${ }^{14}$ Data were normalized to the response of $100 \mu \mathrm{M}$ forskolin.

ERK1/2 Phosphorylation. Cells $\left(2.5 \times 10^{4}\right.$ cells/well $)$ were seeded into 96-well culture plates and incubated overnight. Initially, pERK $1 / 2$ time-course experiments were performed over $30 \mathrm{~min}$ to identify the time point when the pERK1/2 response is maximal $(6-8 \mathrm{~min})$. Subsequently, this time point was selected to generate concentration response for different agonists with ligand addition performed after overnight serum starvation. pERK1/2 was detected using an 


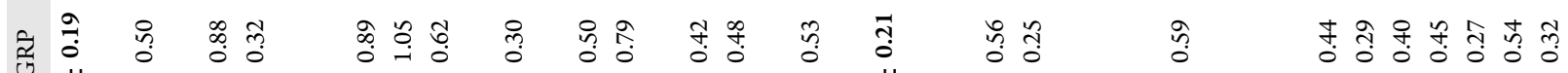

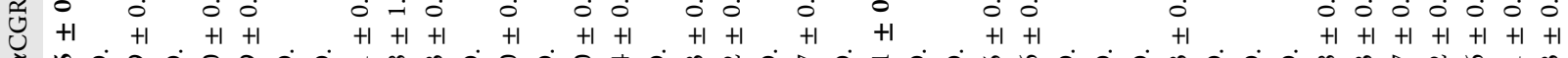

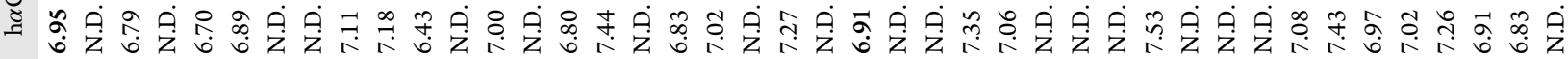

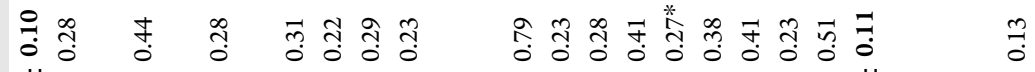

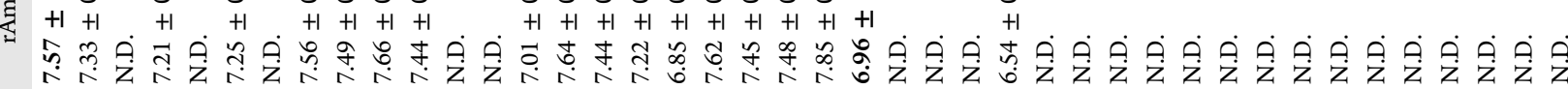

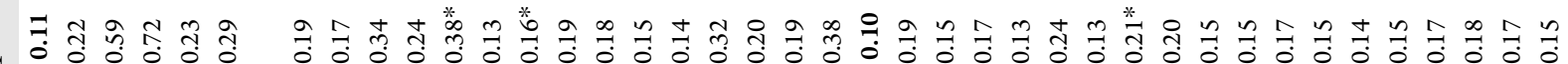
$2,+1+1+1+1+1+1+1+1+1+1+1+1+1+1+1+1+1+1+1+1+1+1+1+1+1+1+1+1+1+1+1+1+1+1+1+1+1+1+1$

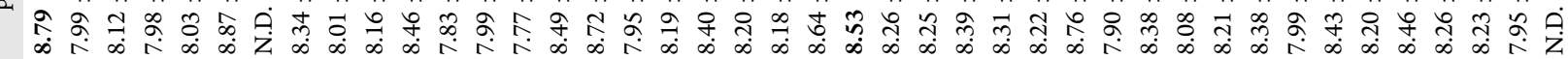

च. $5+1+1+1+1+1 \quad+1+1+1+1+1+1+1+1+1+1+1+1+1+1+1+1+1+1+1+1+1+1+1+1+1+1+1+1+1+1+1+1+1+1$

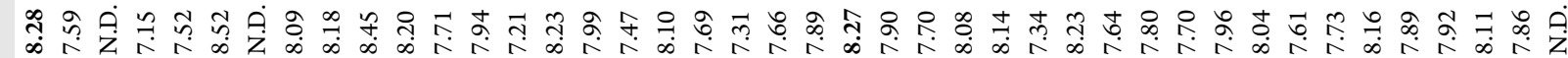

능 융 웡 $+1+1+1+1+1+1+1+1+1+1+1+1+1+1+1+1+1+1+1+1+1+1+1+1+1+1+1+1+1+1+1+1+1+1+1+1+1+1+1+1$

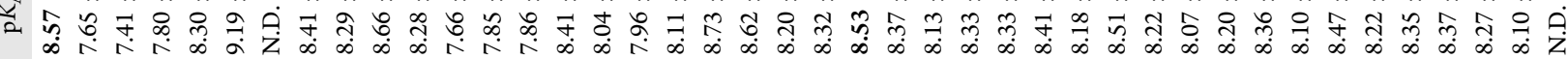

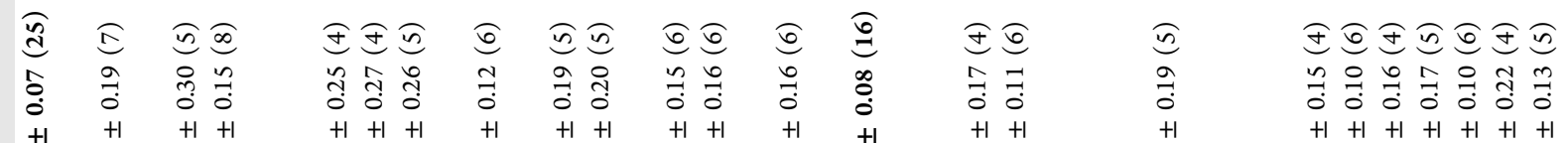
त्ञ

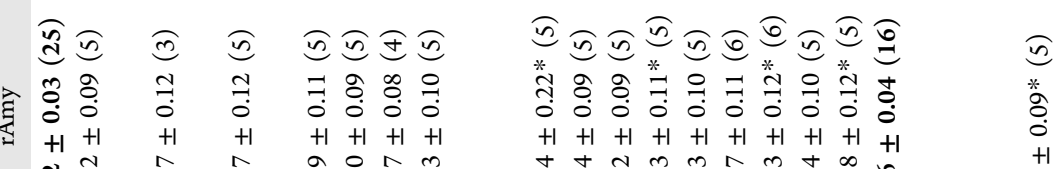

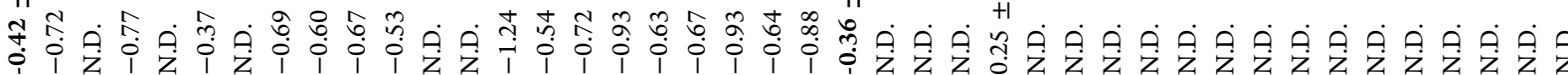

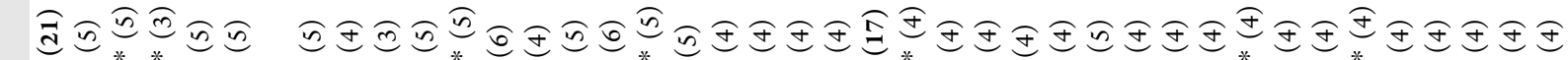

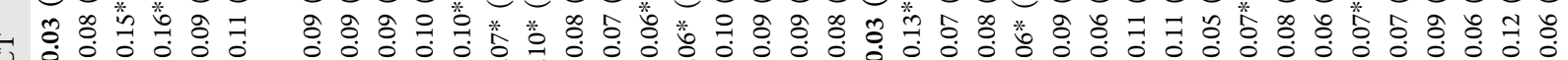

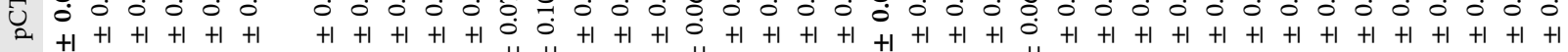

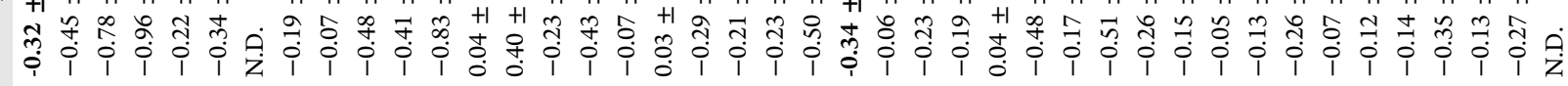

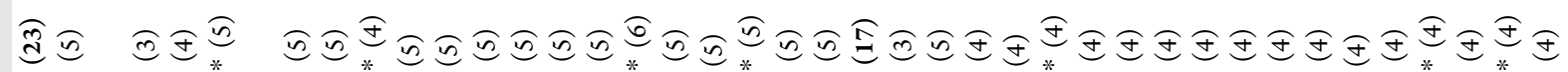
ఛ

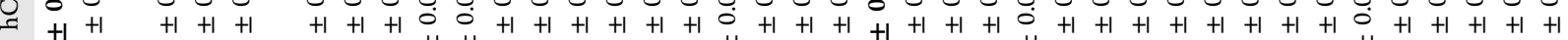

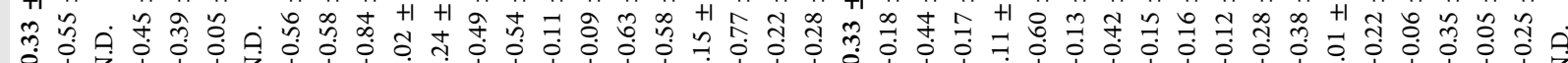

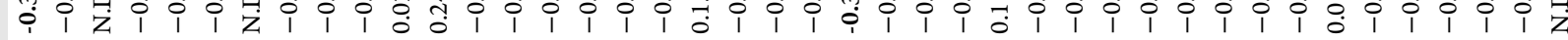

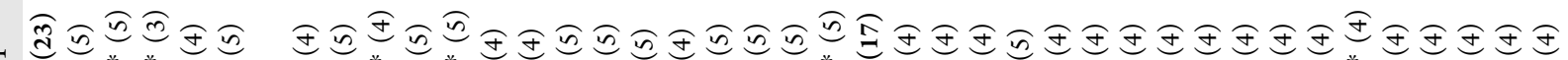
응

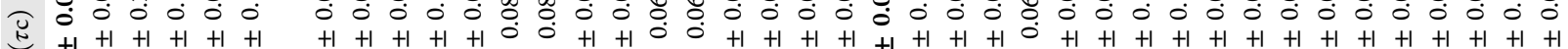

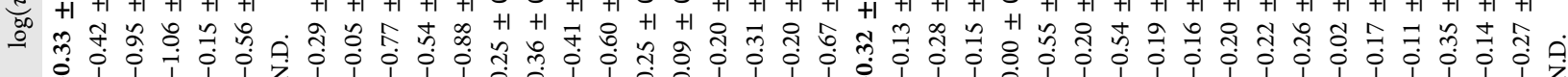


AlphaScreen assay as previously described. ${ }^{26}$ Data were normalized to the maximal response elicited by $10 \%$ FBS determined at $6 \mathrm{~min}$.

Pharmacological Data Analysis. $\mathrm{IC}_{50}$ and $B_{\max }$ values were estimated from competitive inhibition of ${ }^{125} \mathrm{I}_{-} \mathrm{sCT}_{(8-32)}$ binding using a three-parameter logistic equation [log(inhibitor versus response)] in Prism (v7 or v8; GraphPad). Data were corrected for radioligand occupancy using the Cheng-Prusoff equation in Prism, as such data are reported as $\mathrm{p} K_{\mathrm{i}} . E_{\max }$ and $\mathrm{EC}_{50}$ were estimated from concentrationresponse curves using a 3-parameter logistic equation in Prism. These values are a composite of functional affinity, efficacy, and stimulus response coupling. The Black and Leff operational model of agonism ${ }^{21,27}$ was applied to separate effects on pathway-specific efficacy (defined by the value tau, $\tau$ ) from those that modify ligand functional affinity $\left(\mathrm{p} K_{\mathrm{A}}\right)$. Derived $\tau$ values were normalized to experimentally determined levels of cell surface expression to provide a measure of efficacy $(\tau \mathrm{c})$ that is independent of affinity and altered cell surface receptor expression. ${ }^{27} \mathrm{p} K_{\mathrm{i}}, \mathrm{p} K_{\mathrm{A}}$, and $\log \tau \mathrm{c}$ values for mutant receptors were statistically compared to those of the respective WT receptor using a one-way analysis of variance (ANOVA) and Dunnett's post-test. Significance was accepted at $P<0.05$.

3D Cryo-EM Map Reconstruction. Data Processing. Complex purification and data collection were described in the original publication. ${ }^{1} \mathrm{We}$ reprocessed the raw movies using RELION $2.1^{28}$ and RELION $3.0^{29}$ to gain a map at a significantly higher resolution of the ECLs and the peptide ligand. Raw movies were corrected for stage drift and beaminduced motion using MotionCor2.1. ${ }^{30}$ Contrast transfer function (CTF) estimation was done using Gctf software ${ }^{31}$ using the nondose-weighted micrographs. All subsequent steps were performed in RELION. Autopicked particles $(\sim 1.4 \mathrm{M}$ particles) were extracted using a 180 pixel box size (1.06 $\AA$ / pix) and subjected to $2 \mathrm{D}$ classification in Relion 2.1, followed by $3 \mathrm{D}$ classification using the denovo generated initial model. The combination of the three best classes (417949 particles) yielded a $4.05 \AA$ map, similar to the one we deposited previously ${ }^{1}$, albeit with $\sim 3 \times$ more particles). These particles were used for further data processing. First, the highly mobile $\mathrm{G} \alpha \mathrm{s} \alpha$-helical domain and the detergent micelle were removed using signal subtraction protocols in RELION. Specifically, we created a mask encompassing only the protein component of the complex (and without the $\alpha$-helical domain), subtracted it from the refined map of the entire complex and used the resulting mask for signal-subtraction. 3D-autorefinement of the signal-subtracted particles yielded a $3.4 \AA$ map. Signal subtraction of the N-terminal ECD did not yield further improvements in map quality. After the release of RELION 3.0, we applied Bayesian Polishing, and this yielded a final map at $3.34 \AA$ resolution. While the Bayesian Polishing did not improve the resolution numerically, the map quality was improved significantly. During refinement, a regularization parameter was used to relax the low-pass filter effect of the Wiener filter $(T=3)$ as performed as previously described, ${ }^{32,33}$ while keeping half-maps completely separate and basing the resolution on the standard Fourier shell correlation (FSC) at the postprocessing stage in RELION. The final map was sharpened in RELION with a $B$-factor of $-40 \AA$ (RELION sharpening) or alternatively using LocalDeblur (LocalDeblur map $^{34}$ ). Local resolution was determined using RELION 3.0.

Modeling. The previously deposited CTR complex model (PDB-5UZ7) served as an initial model. Manual remodeling 


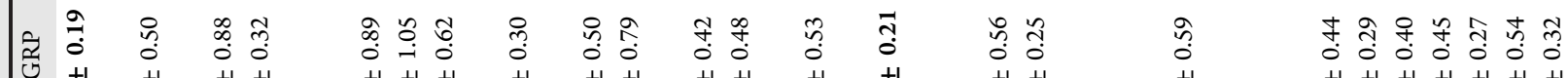

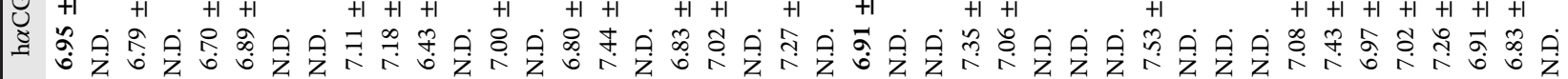

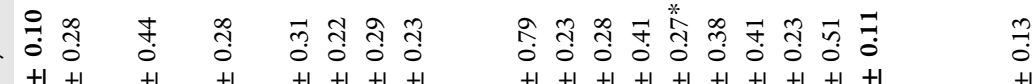

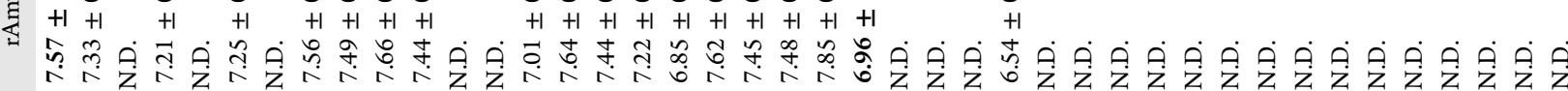

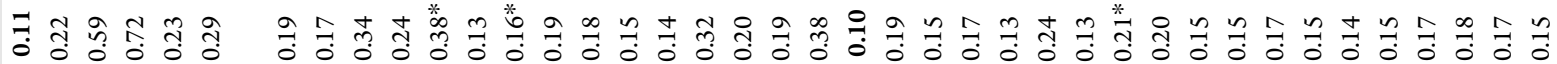
$\simeq 5+1+1+1+1+1+1+1+1+1+1+1+1+1+1+1+1+1+1+1+1+1+1+1+1+1+1+1+1+1+1+1+1+1+1+1+1+1+1+1$

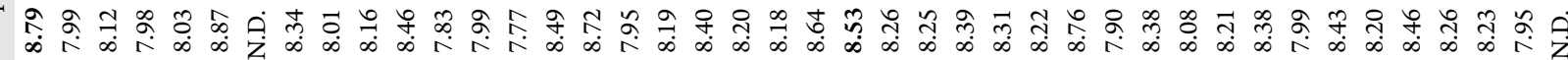

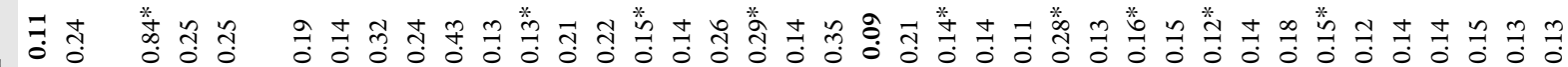
$5+1+1 \quad+1+1+1 \quad+1+1+1+1+1+1+1+1+1+1+1+1+1+1+1+1+1+1+1+1+1+1+1+1+1+1+1+1+1+1+1+1+1+1$

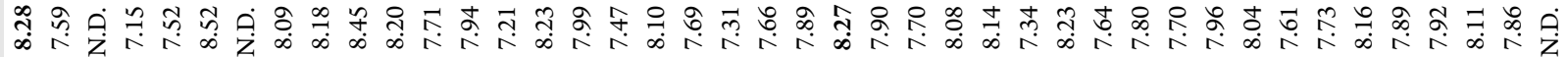

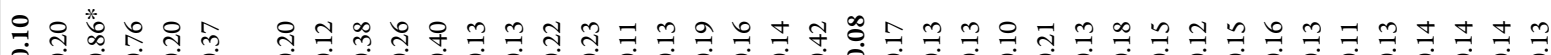

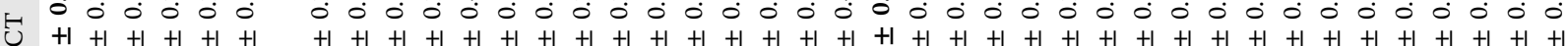

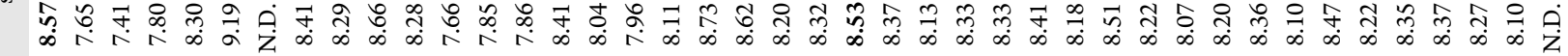

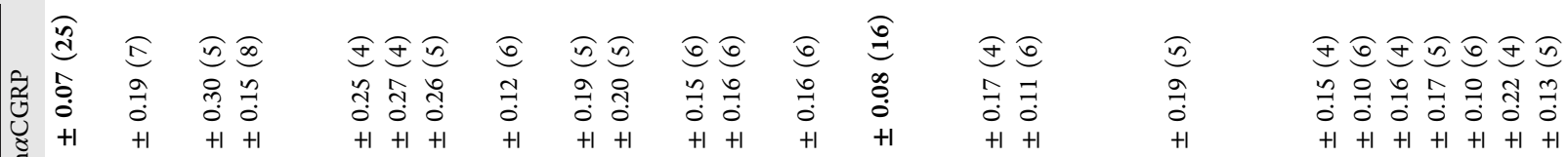

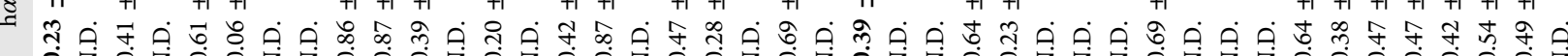

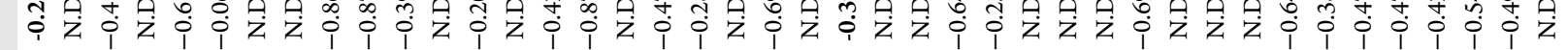

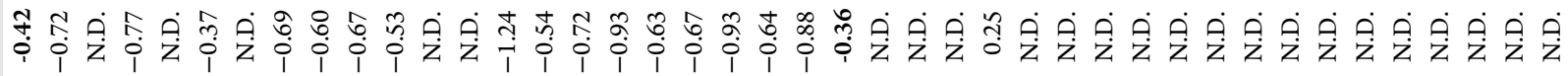

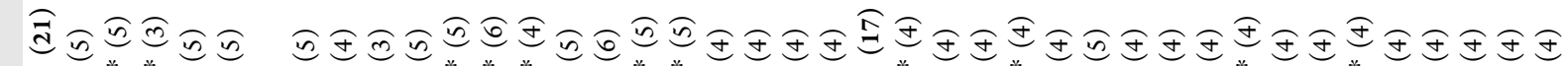
o o

$$
\text { 章 }
$$

节

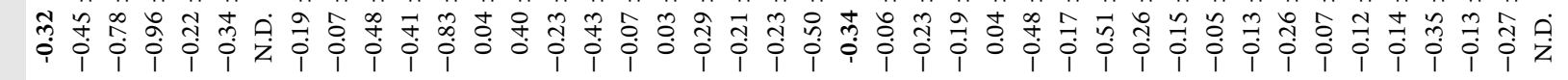

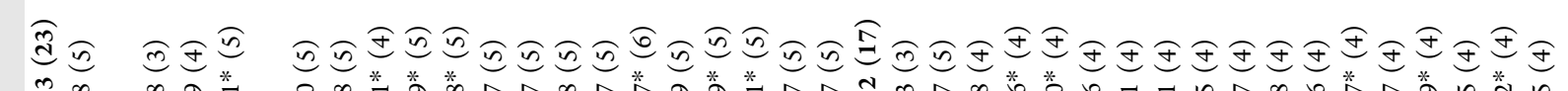

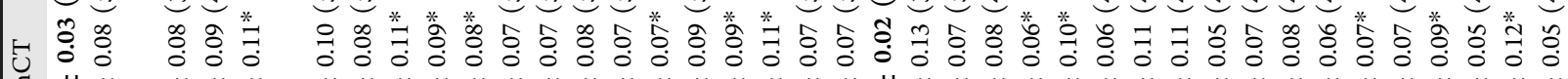

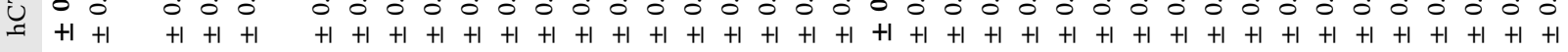

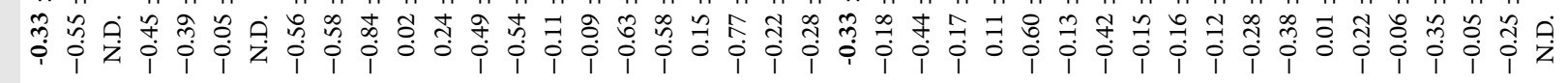

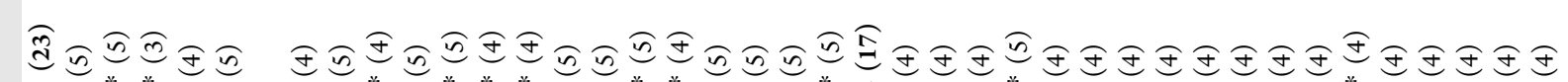

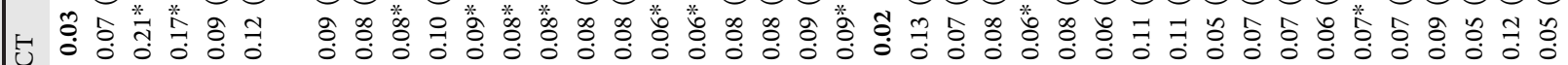

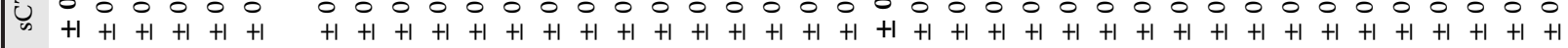

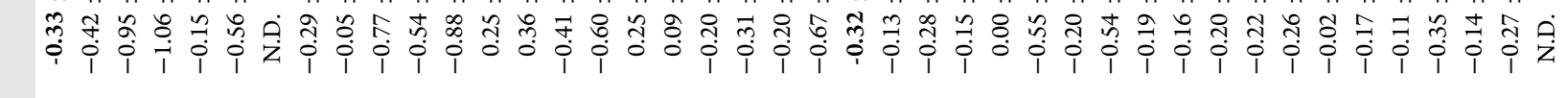

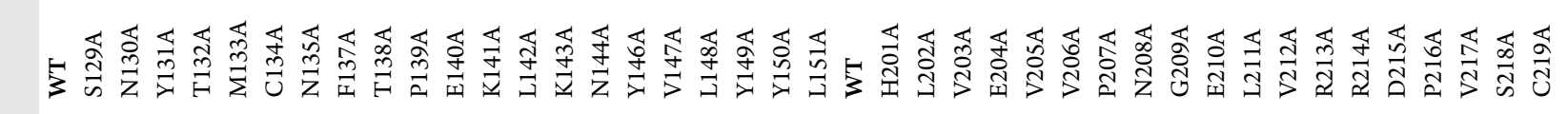




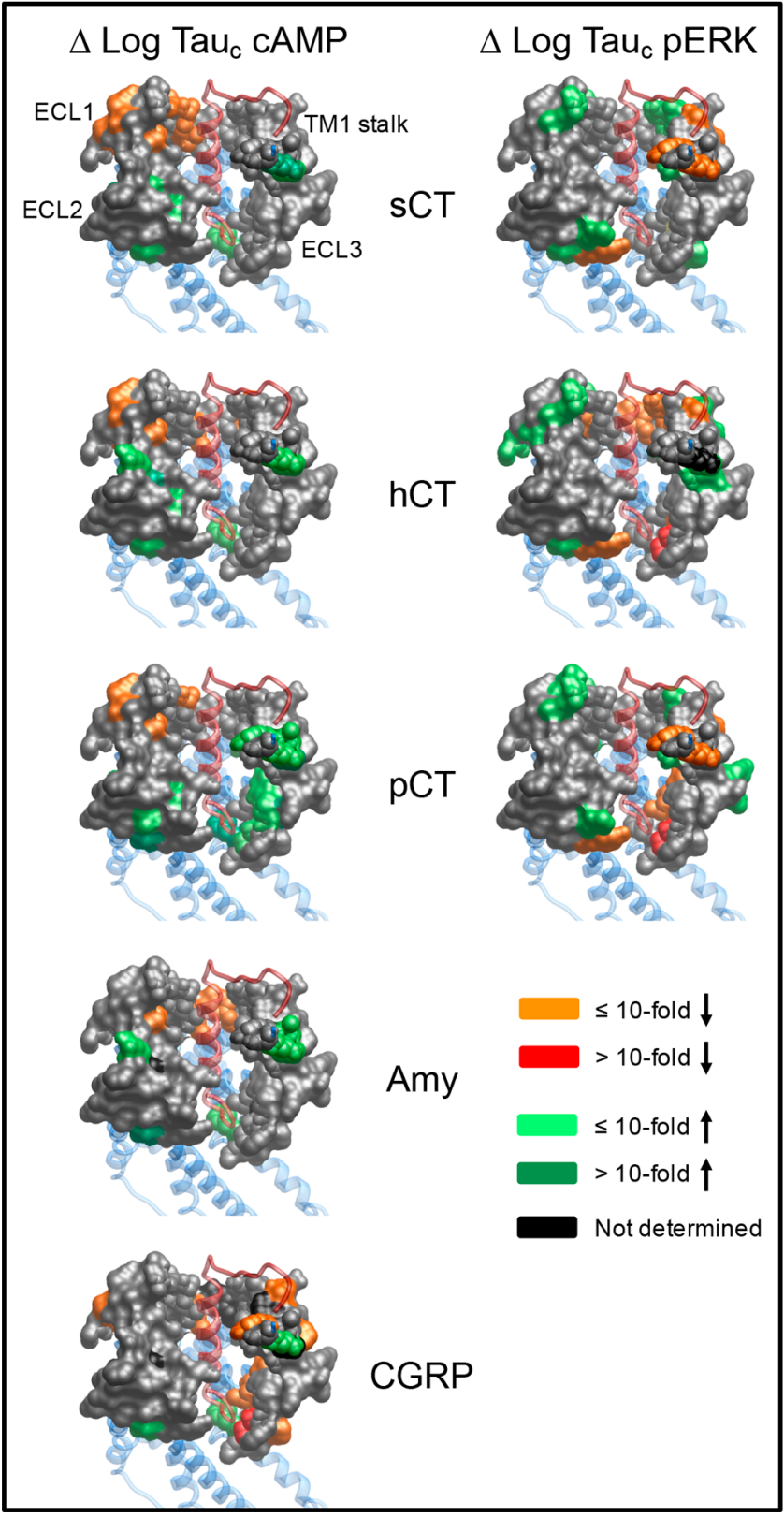

Figure 15. Alanine mutation of the extracellular surface of the CTR reveals markedly different mechanisms for efficacy propagation for cAMP accumulation and pERK. Efficacy values $\left(\log \operatorname{tau}_{\mathrm{c}}\right.$ ) derived from operational fitting of concentration-response curves in cAMP accumulation (LHS) and pERK (RHS) are displayed as $\Delta$ Log Tau from the WT. Illustrated is a top view of the active, sCT-bound, CTR model with the extracellular surface subject to alanine scanning depicted (combined surface/cpk representation). Mutations that significantly alter peptide efficacy are colored according to the magnitude of effect, with mutated amino acids without significant alteration to $\log K_{\mathrm{A}}$ colored gray. $\mathrm{sCT}$ is shown as dark red, in ribbon representation. Amino acid mutations where there was an insufficiently robust functional effect to quantify by operational modeling are depicted in black. The receptor ECD is not shown for clarity.

was done in $\mathrm{COOT},{ }^{35}$ followed by real space refinement using "phenix.real space refine" in PHENIX. ${ }^{36}$ Model validation was performed using MolProbity. ${ }^{37}$ Validation of model overfitting to the cryo-EM maps was performed as described previously. ${ }^{38}$ Figures were prepared in USCF Chimera ${ }^{39}$ or 
Molsoft ICM. Ligand-receptor interactions were also assessed and illustrated using LigPlot $^{+}$(v2.01). ${ }^{40}$

The CTR complex mode is deposited as PDB 6NIY and the unprocessed, RELION postprocessed, and LocalDeblur postprocessed maps are deposited in the EMDB, EMD-9382.

Completing the CTR Structure. A hybrid CTR/CGRPR structure was built in which the bulk of the amino acid sequence was taken from CTR, but with ECL1 initially taken from the CGRPR sequence, as this structure is present in the active CGRPR complex PDB (PDB 6E3Y) $;^{15}$ this was used to replace the missing residues by the process of molecular superposition using ccp4 mg. ${ }^{41}$ The homology modeling module of $\mathrm{PLOP}^{42}$ was then used to mutate the hybrid structure completely to CTR while adding the missing residues. The structure was preprocessed using the Schrödinger Protein Preparation Wizard (Maestro version 9.8, Schrödinger LLC, NY), which flagged molecular clashes. As a result, Lys $18^{\mathrm{P}}$ of $\mathrm{sCT}$ was rebuilt using PLOP, while the remaining steric clashes were removed through minimization using PLOP.

Molecular Dynamics (MD) Simulations. CTR in complex with sCT and the $\mathrm{C}$-terminus of the $\mathrm{G}$ protein $\alpha$ subunit $\left(\alpha_{370-394}\right)$ was prepared for MD simulations with the CHARMM36 force field ${ }^{43}$ using a multistep procedure that combines python htmd ${ }^{44}$ and tcl (Tool Command Language) scripts. Hydrogen atoms were first added by means of the pdb $2 \mathrm{pqr}^{45}$ and propka ${ }^{46}$ software (considering a simulated $\mathrm{pH}$ of 7.0); the protonation of titratable side chains was checked by visual inspection. The system CTR:sCT:G $\alpha_{370-394}$ was embedded in a square $106 \AA \times 106 \AA$ 1-palmitoyl-2-oleyl-snglycerol-3-phospho-choline (POPC) bilayer (previously built by using the VMD Membrane Builder plugin 1.1, Membrane Plugin, version 1.1. at http://www.ks.uiuc.edu/Research/vmd/ plugins/membrane/) through an insertion method. ${ }^{47}$ The receptor orientation was obtained by superposing CTR coordinates on the CTR-Gs complex (PDB 5UZ7) structure retrieved from the OPM database. ${ }^{48}$ Lipids overlapping the receptor TM bundle were removed and TIP3P water molecules ${ }^{49}$ were added to the simulation box $(106 \AA \times 106$ $\AA \times 136 \AA$ ) by means of the VMD Solvate plugin 1.5 (Solvate Plugin, version 1.5. at http://www.ks.uiuc.edu/Research/vmd/ plugins/solvate/). Overall charge neutrality was finally reached by adding $\mathrm{Na}^{+} / \mathrm{Cl}^{-}$counterions (final ionic strength of 0.150 $\mathrm{M}$ ), using the VMD Autoionize plugin 1.3 (Autoionize Plugin, version 1.3, http://www.ks.uiuc.edu/Research/vmd/plugins/ autoionize/).

Systems Equilibration and MD Settings. The MD engine ACEMD ${ }^{50}$ was employed for both the equilibration and productive simulations. Equilibration was achieved in isothermal-isobaric conditions (NPT) using the Berendsen barostat $^{51}$ (target pressure $1 \mathrm{~atm}$ ) and the Langevin thermo$\operatorname{stat}^{52}$ (target temperature $300 \mathrm{~K}$ ) with a low damping of 1 $\mathrm{ps}^{-1}$. A three-stage procedure was performed (integration time step of $2 \mathrm{fs}$ ). In the first stage, clashes between protein and lipid atoms were reduced through 2500 conjugate-gradient minimization steps, then a $2 \mathrm{~ns}$ long MD simulation was run with a positional constraint of $1 \mathrm{kcal} \mathrm{mol}^{-1} \AA^{-2}$ on protein and lipid phosphorus atoms. In the second stage, $33 \mathrm{~ns}$ of $\mathrm{MD}$ simulation were performed constraining only the protein atoms. Finally, in the third stage, positional constraints were applied only to the protein backbone alpha carbons, for a further 2 ns.

Three replicas of $200 \mathrm{~ns}$ long each were computed with an integration time step of 4 fs in the canonical ensemble (NVT) at $300 \mathrm{~K}$, using a thermostat damping of $0.1 \mathrm{ps}^{-1}$ and the MSHAKE algorithm ${ }^{53}$ to constrain the bond lengths involving hydrogen atoms. The cutoff distance for electrostatic interactions was set at $9 \AA$, with a switching function applied beyond 7.5 Å. Long range Coulomb interactions were handled using the particle mesh Ewald summation method (PME) $)^{54}$ by setting the mesh spacing to $1.0 \AA$.

\section{ASSOCIATED CONTENT}

\section{Supporting Information}

The Supporting Information is available free of charge on the ACS Publications website at DOI: 10.1021/acsptsci.8b00056.

Atomic resolution models; concentration-response curves; competition binding isotherms (PDF)

\section{AUTHOR INFORMATION}

\section{Corresponding Authors}

*E-mail: Patrick.sexton@monash.edu.

*E-mail: denise.wootten@monash.edu.

ORCID

Sebastian G. B. Furness: 0000-0001-8655-8221

Debbie L. Hay: 0000-0002-9558-5122

Patrick M. Sexton: 0000-0001-8902-2473

\section{Author Contributions}

\#E.d.M. and A.G. contributed equally to this work. The following contributions were made: contributed to experimental design (E.d.M., D.L.H., M.-W.W., D.W., P.M.S.); performed experiments (E.d.M., Y.Z., C.A.H., Y.-L.L.); contributed to conceptual development of the project (S.G.B.F., D.L.H., A.C., L.J.M., M.-W.W., D.W., P.M.S.); performed data EM analysis (A.G., J.G.-N., C.G.T., E.R., J.M.C.); performed modeling of the protein into the E.M. map (A.G.); performed molecular modeling (S.A., C.A.R.); performed pharmacological data analysis (E.d.M., D.W., P.M.S.); contributed to production of figures (E.d.M., A.G., D.W., P.M.S.); provided oversight of the project (D.W., P.M.S.); edited the manuscript (all authors); drafted the manuscript (P.M.S).

\section{Notes}

The authors declare no competing financial interest.

\section{ACKNOWLEDGMENTS}

This work was supported by the National Health and Medical Research Council of Australia (NHMRC) program Grant 1055134 and project Grants 1061044, 1159006, Shanghai Science and Technology Development Fund (15DZ2291600), the Chinese Academy of Sciences (CAS)-Novo Nordisk Research Fund, and the Biotechnology and Biological Sciences Research Council (BBSRC; BB/M006883/1). A.G. is an Australian Research Council (ARC) Discovery Early Career Research Award Fellow. S.F. is an ARC Future Fellow. D.W. is a Senior Research Fellow, and A.C. and P.M.S. are Senior Principal Research Fellows, of the NHMRC. D.L.H. is a James Cook Research Fellow of the Royal Society of New Zealand. C.A.R. is a Royal Society Industrial Fellow. S.A. is supported by the Peter Nicholls bequest. Data processing for map reconstruction was performed on the Monash University MASSIVE M3 high performance computing cluster. 


\section{REFERENCES}

(1) Liang, Y.-L., Khoshouei, M., Radjainia, M., Zhang, Y., Glukhova, A., Tarrasch, J., Thal, D. M., Furness, S. G. B., Christopoulos, G., Coudrat, T., Danev, R., Baumeister, W., Miller, L. J., Christopoulos, A., Kobilka, B. K., Wootten, D., Skiniotis, G., and Sexton, P. M. (2017) Phase-plate cryo-EM structure of a class B GPCR-G protein complex. Nature 546, 118-123.

(2) Wootten, D., Miller, L. J., Koole, C., Christopoulos, A., and Sexton, P. M. (2017) Allostery and Biased Agonism at Class B G Protein-Coupled Receptors. Chem. Rev. 117, 111-138.

(3) Ostrovskaya, A., Findlay, D. M., Sexton, P. M., and Furness, S. G. B. (2017). Calcitonin. Reference Module in Neuroscience and Biobehavioral Psychology, 1-12. DOI: 10.1016/B978-0-12-8093245.03223-5, Elsevier.

(4) Hay, D. L., Garelja, M. L., Poyner, D. R., and Walker, C. S. (2018) Update on the pharmacology of calcitonin/ CGRP family of peptides: IUPHAR Review 25. Br. J. Pharmacol. 175, 3-17.

(5) Graaf, C. D., Donnelly, D., Wootten, D., Lau, J., Sexton, P. M., Miller, L. J., Ahn, J. M., Liao, J., Fletcher, M. M., Yang, D., Brown, A. J., Zhou, C., Deng, J., and Wang, M. W. (2016) Glucagon-Like Peptide-1 and Its Class B G Protein-Coupled Receptors: A Long March to Therapeutic Successes. Pharmacol. Rev. 68, 954-1013.

(6) Russo, A. F. (2018) CGRP-Based Migraine Therapeutics: How Might They Work, Why So Safe, and What Next? ACS Pharmacol Transl Sci., 1 in press DOI: 10.1021/acsptsci.8b00036.

(7) Findlay, D. M., Sexton, P. M., and Martin, T. J. (2015) Calcitonin. Endocrinology: Adult \& Pediatric, (Jameson, J. L., De Groot, L. J., de Kretser, D. M., Giudice, L. C., Grossman, A. B. Melmed, S., Potts, J. T., Jr, and Weir, G. C. Eds.) 7th ed., Vols 1 and 2, pp 1004-101714, Elsevier, Philadelphia, PA USA.

(8) Furness, S. G. B., Liang, Y.-L., Nowell, C. J., Halls, M. L., Wookey, P. J., Dal Maso, E., Inoue, A., Christopoulos, A., Wootten, D., and Sexton, P. M. (2016) Ligand-dependent modulation of G protein conformation alters drug efficacy. Cell 167, 739-749.

(9) Dal Maso, E., Just, R., Hick, C., Christopoulos, A., Sexton, P. M., Wootten, D., and Furness, S. G. B. (2018) Characterisation of signaling and regulation of common calcitonin receptor splice variants and polymorphisms. Biochem. Pharmacol. 148, 111-129.

(10) Andreassen, K. V., Hjuler, S. T., Furness, S. G., Sexton, P. M., Christopoulos, A., Nosjean, O., Karsdal, M. A., and Henriksen, K. (2014) Prolonged calcitonin receptor signaling by salmon, but not human calcitonin, reveals ligand bias. PLoS One 9, No. e92042.

(11) Dal Maso, E., Zhu, Y., Pham, V., Reynolds, C. A., Deganutti, G., Hick, C. A., Yang, D., Christopoulos, A., Hay, D. L., Wang, M.-W., Sexton, P. M., Furness, S. G. B., and Wootten, D. (2018) Extracellular loops 2 and 3 of the calcitonin receptor selectively modify agonist binding and efficacy. Biochem. Pharmacol. 150, 214-244.

(12) Wootten, D., Simms, J., Miller, L. J., Christopoulos, A., and Sexton, P. M. (2013) Polar transmembrane interactions drive formation of ligand-specific and signal pathway-biased Family B GPCR conformations. Proc. Natl. Acad. Sci. U. S. A. 110, 5211-5216.

(13) Zhang, Y., Sun, B., Feng, D., Hu, H., Chu, M., Qu, Q., Tarrasch, J. T., Li, S., Kobilka, T. S., Kobilka, B. K., and Skiniotis, G. (2017) Cryo-EM structure of the activated GLP-1 receptor in complex with a G protein. Nature 546, 248-253.

(14) Liang, Y.-L., Khoshouei, M., Glukhova, A., Furness, S. G. B., Zhao, P., Clydesdale, L., Koole, C., Troung, T. T., Thal, D. M., Lei, S., Radjainia, M., Danev, R., Baumeister, W., Wang, M.-W., Miller, L. J., Christopoulos, A., Sexton, P. M., and Wootten, D. (2018) Phase-plate cryo-EM structure of a biased agonist-bound human GLP-1 receptorGs complex. Nature 555, 121-125.

(15) Liang, Y.-L., Khoshouei, M., Deganutti, G., Glukhova, A., Koole, C., Peat, T. S., Radjainia, M., Plitzko, J. M., Baumeister, W., Miller, L. J., Hay, D. L., Christopoulos, A., Reynolds, C. A., Wootten, D., and Sexton, P. M. (2018) Cryo-EM structure of the active, Gsprotein complexed, human CGRP receptor. Nature 561, 492-497.

(16) Glukhova, A., Draper-Joyce, C. J., Sunahara, R. K., Christopoulos, A., Wootten, D., and Sexton, P. M. (2018) Rules of engagement: GPCRs and G proteins. ACS Pharmacol. Transl. Sci. 1, 73-83.

(17) Houssami, S., Findlay, D. M., Brady, C. L., Martin, T. J., Epand, R. M., Moore, E. E., Murayama, E., Tamura, T., Orlowski, R. C., and Sexton, P. M. (1995) Divergent structural requirements exist for calcitonin receptor binding specificity and adenylate cyclase activation. Mol. Pharmacol. 47, 798-809.

(18) Johansson, E., Hansen, J. L., Hansen, A. M., Shaw, A. C., Becker, P., Schäffer, L., and Reedtz-Runge, S. (2016) Type II Turn of Receptor-bound Salmon Calcitonin Revealed by X-ray Crystallography. J. Biol. Chem. 291, 13689-13698.

(19) Hilton, J. M., Dowton, M., Houssami, S., and Sexton, P. M. (2000) Identification of key components in the irreversibility of salmon calcitonin binding to calcitonin receptors. J. Endocrinol. 166, 213-226.

(20) Morfis, M., Tilakaratne, N., Furness, S. G. B., Christopoulos, G., Werry, T. D., Christopoulos, A., and Sexton, P. M. (2008) Receptor activity modifying proteins differentially modulate the $G$ proteincoupling efficiency of amylin receptors. Endocrinology 149, 54235431.

(21) Black, J. W., and Leff, P. (1983) Operational models of pharmacological agonism. Proc. R Soc. Lond B Biol. Sci. 220, 141-162.

(22) Mackie, D. I., Al Mutairi, F., Davis, R. B., Kechele, D. O., Nielsen, N. R., Snyder, J. C., Caron, M. G., Kliman, H. J., Berg, J. S., Simms, J., Poyner, D. R., and Caron, K. M. (2018) hCALCRL mutation causes autosomal recessive nonimmune hydrops fetalis with lymphatic dysplasia. J. Exp. Med. 215, 2339-2353.

(23) Lei, S., Clydesdale, L., Dai, A., Cai, X., Feng, Y., Yang, D., Liang, Y.-L., Koole, C., Zhao, P., Coudrat, T., Christopoulos, A., Wang, M.W., Wootten, D., and Sexton, P. M. (2018) Two distinct domains of the glucagon-like peptide-1 receptor control peptide-mediated biased agonism. J. Biol. Chem. 293, 9370-9387.

(24) Wootten, D., Reynolds, C. A., Smith, K. J., Mobarec, J. C., Koole, C., Savage, E. E., Pabreja, K., Simms, J., Sridhar, R., Furness, S. G. B., Liu, M., Thompson, P. E., Miller, L. J., Christopoulos, A., and Sexton, P. M. (2016) The GLP-1 receptor extracellular surface is a molecular trigger for biased agonism. Cell 165, 1632-1643.

(25) Watkins, H. A., Chakravarthy, M., Abhayawardana, R. S., Gingell, J. J., Garelja, M., Pardamwar, M., McElhinney, J. M., Lathbridge, A., Constantine, A., Harris, P. W., Yuen, T. Y., Brimble, M. A., Barwell, J., Poyner, D. R., Woolley, M. J., Conner, A. C., Pioszak, A. A., Reynolds, C. A., and Hay, D. L. (2016) Receptor activity-modifying proteins 2 and 3 generate adrenomedullin receptor subtypes with distinct molecular properties. J. Biol. Chem. 291, 11657-11675.

(26) Koole, C., Wootten, D., Simms, J., Valant, C., Sridhar, R., Woodman, O. L., Miller, L. J., Summers, R. J., Christopoulos, A., and Sexton, P. M. (2010) Allosteric ligands of the glucagon-like peptide 1 receptor (GLP-1R) differentially modulate endogenous and exogenous peptide responses in a pathway-selective manner; implications for drug screening. Mol. Pharmacol. 78, 456-465.

(27) Koole, C., Wootten, D., Simms, J., Miller, L. J., Christopoulos, A., and Sexton, P. M. (2012) The second extracellular loop of the human glucagon-like peptide-1 receptor (GLP-1R) has a critical role in GLP-1 peptide binding and receptor activation. J. Biol. Chem. 287, $3642-3648$.

(28) Kimanius, D., Forsberg, B. O., Scheres, S. H., and Lindahl, E. (2016) Accelerated cryo-EM structure determination with parallelisation using GPUs in RELION-2. eLife 5, 19.

(29) Zivanov, J., Nakane, T., Forsberg, B. O., Kimanius, D., et al. (2018) New tools for automated high-resolution cryo-EM structure determination in RELION-3. eLife 7, 163.

(30) Zheng, S. Q., et al. (2017) MotionCor2: anisotropic correction of beam-induced motion for improved cryo-electron microscopy. Nat. Methods 14, 331-332.

(31) Zhang, K. (2016) Gctf: Real-time CTF determination and correction. J. Struct. Biol. 193, 1-12. 
(32) García-Nafría, J., Lee, Y., Bai, X., Carpenter, B., and Tate, C. G. (2018) Cryo-EM structure of the adenosine A2A receptor coupled to an engineered heterotrimeric G protein. eLife 7, No. e35946.

(33) García-Nafría, J., Nehmé, R., Edwards, P. C., and Tate, C. G. (2018) Cryo-EM structure of the serotonin 5-HT1B receptor coupled to heterotrimeric Go. Nature 558, 620-623.

(34) Ramirez-Aportela, E., Vilas, J. L., Melero, R., Conesa, P., Martinez, M., Maluenda, D., Mota, J., Jimenez, A., Vargas, J., Marabini, R., Carazo, J. M., and Sorzano, C. O. S. (2018)Automatic local resolution-based sharpening of cryo-EM maps. bioRxiv DOI: $10.1101 / 433284$.

(35) Emsley, P., Lohkamp, B., Scott, W. G., and Cowtan, K. (2010) Features and development of Coot. Acta Crystallogr., Sect. D: Biol. Crystallogr. 66, 486-501.

(36) Adams, P. D., et al. (2010) PHENIX: a comprehensive Pythonbased system for macromolecular structure solution. Acta Crystallogr., Sect. D: Biol. Crystallogr. 66, 213-221.

(37) Chen, V. B., et al. (2010) MolProbity: all-atom structure validation for macromolecular crystallography. Acta Crystallogr., Sect. D: Biol. Crystallogr. 66, 12-21.

(38) Draper-Joyce, C. J., Khoshouei, M., Thal, D., Liang, Y.-L., Nguyen, A. T. N., Furness, S. G. B., Venugopal, H., Baltos, J., Plitzko, J. M., Danev, R., Baumeister, W., May, L. T., Wootten, D., Sexton, P. M., Glukhova, A., and Christopoulos, A. (2018) Structure of the adenosine-bound human adenosine A1 receptor-Gi complex. Nature 558, 559-563.

(39) Pettersen, E. F., et al. (2004) UCSF Chimera-a visualization system for exploratory research and analysis. J. Comput. Chem. 25, $1605-1612$.

(40) Laskowski, R. A., and Swindells, M. B. (2011) LigPlot+: multiple ligand-protein interaction diagrams for drug discovery. $J$. Chem. Inf. Model. 51, 2778-2786.

(41) McNicholas, S., Potterton, E., Wilson, K. S., and Noble, M. E. (2011) Presenting your structures: the CCP4mg molecular-graphics software. Acta Crystallogr., Sect. D: Biol. Crystallogr. 67, 386-394.

(42) Goldfeld, D. A., Zhu, K., Beuming, T., and Friesner, R. A. (2011) Successful prediction of the intra- and extracellular loops of four G-protein-coupled receptors. Proc. Natl. Acad. Sci. U. S. A. 108, $8275-8280$.

(43) Huang, J., and MacKerell, A. D. (2013) CHARMM36 all-atom additive protein force field: validation based on comparison to NMR data. J. Comput. Chem. 34, 2135-2145.

(44) Doerr, S., Harvey, M. J., Noé, F., and De Fabritiis, G. (2016) HTMD: High-Throughput Molecular Dynamics for Molecular Discovery. J. Chem. Theory Comput. 12, 1845-1852.

(45) Dolinsky, T. J., Nielsen, J. E., McCammon, J. A., and Baker, N. A. (2004) PDB2PQR: an automated pipeline for the setup of PoissonBoltzmann electrostatics calculations. Nucleic Acids Res. 32, W665W667.

(46) Olsson, M. H. M., Søndergaard, C. R., Rostkowski, M., and Jensen, J. H. (2011) PROPKA3: Consistent Treatment of Internal and Surface Residues in Empirical pKa Predictions. J. Chem. Theory Comput. 7, 525-537.

(47) Sommer, B. (2013) Membrane Packing Problems: A short Review on computational Membrane Modeling Methods and Tools. Comput. Struct. Biotechnol. J. 5, No. e201302014.

(48) Lomize, M. A., Lomize, A. L., Pogozheva, I. D., and Mosberg, H. I. (2006) OPM: orientations of proteins in membranes database. Bioinformatics 22, 623-625.

(49) Jorgensen, W. L., Chandrasekhar, J., Madura, J. D., Impey, R. W., and Klein, M. L. (1983) Comparison of simple potential functions for simulating liquid water. J. Chem. Phys. 79, 926-935.

(50) Harvey, M. J., Giupponi, G., and De Fabritiis, G. (2009) ACEMD: Accelerating Biomolecular Dynamics in the Microsecond Time Scale. J. Chem. Theory Comput. 5, 1632-1639.

(51) Berendsen, H. J. C., Postma, J. P. M., van Gunsteren, W. F., DiNola, A., and Haak, J. R. (1984) Molecular dynamics with coupling to an external bath. J. Chem. Phys. 81, 3684-3690.
(52) Loncharich, R. J., Brooks, B. R., and Pastor, R. W. (1992) Langevin dynamics of peptides: the frictional dependence of isomerization rates of $\mathrm{N}$-acetylalanyl-N'-methylamide. Biopolymers 32, 523-535.

(53) Kräutler, V., Van Gunsteren, W. F., and Hünenberger, P. H. (2001) A fast SHAKE algorithm to solve distance constraint equations for small molecules in molecular dynamics simulations. $J$. Comput. Chem. 22, 501-508.

(54) Essmann, U., et al. (1995) A smooth particle mesh Ewald method. J. Chem. Phys. 103, 8577-8593. 